\title{
Stimulation of Phenolic Compounds Accumulation and Antioxidant Activity in In Vitro Culture of Salvia Tebesana Bunge in Response to Nano- $\mathrm{TiO}_{2}$ and Methyl Jasmonate Elicitors
}

\author{
Amin allah Shoja \\ Ferdowsi University of Mashhad \\ Monireh - Cheniany ( $\nabla$ cheniany@um.ac.ir) \\ Ferdowsi University of Mashhad https://orcid.org/0000-0001-6390-1752 \\ Ali Ganjeali \\ Ferdowsi University of Mashhad
}

\section{Research Article}

Keywords: Callus culture, Elicitor, Methyl jasmonate, Nano-titanium dioxide, Phenolic derivatives, Salvia tebesana.

Posted Date: July 27th, 2021

DOI: https://doi.org/10.21203/rs.3.rs-686528/v1

License: (-) This work is licensed under a Creative Commons Attribution 4.0 International License. Read Full License

Version of Record: A version of this preprint was published at Plant Cell, Tissue and Organ Culture (PCTOC) on March 4th, 2022. See the published version at https://doi.org/10.1007/s11240-022-02251-2. 


\section{Abstract}

In the present study, we first attempted to achieve an efficient procedure for optimizing callogenesis from apical meristem and leaf explants of $S$. tebesana on MS media containing different concentrations of BAP alone and in combination with 2,4-D. Then, the inducing effect of nano- $\mathrm{TiO}_{2}\left(10,60\right.$, and $\left.120 \mathrm{mg} \mathrm{L}^{-1}\right)$ and methyl jasmonate $(50,100$, and $200 \mu \mathrm{M})$, as abiotic elicitors were studied on the enhancement of phenolic compounds, rosmarinic acid, and some individual flavonoids as well as antioxidant capacity of callus extracts. According to the results, the highest callogenesis rate (100 and 93.33, respectively) and DW $(0.55 \pm 0.03$ and $0.36 \pm 0.02 \mathrm{~g}$, respectively) per responsive explant were achieved from apical meristem on MS media containing "BAP $1+2,4-D_{1}$ " mg L-1 and from leaf explant on the medium supplemented with "BAP ${ }_{0.5}+2,4-\mathrm{D}_{1}$ " $\mathrm{mg} \mathrm{L}^{-1}$. The elicitation with 10 and $60 \mathrm{mg} \mathrm{L}^{-1}$ nano-TiO $_{2}$

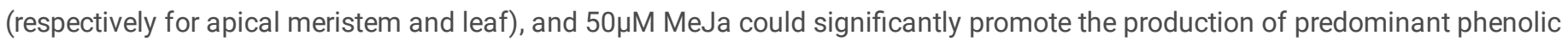
derivatives in S. tebesana calli, where the highest content of total phenolics, $O$-diphenols, phenolic acid, flavonoid, flavone and flavonol, proanthocyanidin was recorded. Additionally, in increasing the amount of rosmarinic acid of callus, nano- $\mathrm{TiO}_{2}$ treatment was more effective than the elicitation with MeJa. Also, the highest content of Apigenin ( $\left.0.33 \pm 0.02 \mu \mathrm{g} \mathrm{g}^{-1} \mathrm{DW}\right)$ was detected after MeJaelicitation $(50 \mu \mathrm{M})$, while the maximum level of Quercetin $\left(2.61 \pm 0.09 \mathrm{\mu g} \mathrm{g}^{-1} \mathrm{DW}\right)$ and Rutin $\left(13.79 \pm 08 \mu \mathrm{g} \mathrm{g}^{-1} \mathrm{DW}\right)$ were obtained after exposure to $60 \mathrm{mg} \mathrm{L}^{-1}$ nano-TiO ${ }_{2}$, both from leaf-derived calli. While a significant positive correlation was recorded between antioxidant assays (DPPH and FRAP) and phenolic derivatives of treated calli; a very strong correlation occurred between the content of rosmarinic acid of apical meristem-derived calli and DPPH and FRAP values $\left(r^{2}=-0.921\right.$ and $r^{2}=-0.913, P<0.01$ respectively). Our results showed that the combination of in vitro culture and elicitation would be a good technique to successfully produce and enhance the content of pharmacologically valuable metabolites in S. tebesana.

\section{Key Message}

Nano- $\mathrm{TiO}_{2}$ and methyl jasmonate elicitors in a concentration-dependent manner increased the phenolic compounds, specific flavonoids, and antioxidant properties in the callus culture of Salvia tebesana Bunge.

\section{Introduction}

Salvia tebesana Bunge is a small shrub plant, which its geographical distribution restricts to Iran, Afghanistan, and Pakistan. In Iran, it has only been reported in a limited area of South Khorasan province (Khatamzaz 2002). This endemic plant belongs to the genus Salvia genus (family Lamiaceae), with over 900 species that have been identified around the world, and about 17 species are endemic to Iran (Walker et al. 2004). Salvia L. contains a large assortment of secondary metabolites, including essential oils, phenolic acids, flavonoids, and terpenoids (Russo et al. 2013). Studies have also shown that phenolic compounds can exhibit a broad range of physiologicaltherapeutic properties, such as anti-inflammatory, anti-allergic, antioxidant, antimicrobial, anti-proliferative activities, anti-thrombotic, and cardiovascular protective effects. Because of high antioxidant activities, phenolic compounds function as the main bioactive compounds to determine the antioxidant power in foods (Ulubelen and Topcu, 1992; Taârit et al. 2012; Aleebrahim-Dehkordy et al. 2016). In addition to high levels of flavonoids (Đorđević et al. 2000; Kamatou et al. 2008), it has been proved that one of the most abundant phenolic acids present in Salvia species is rosmarinic acid (RA)(Bandoniene et al. 2005; Koşar et al. 2008; Jadeja et al. 2014). This compound has also been reported with antibacterial, antiviral, antioxidant, and anti-inflammatory effects (Petersen and Simmonds 2003).

In vitro production of callus-derived secondary metabolites is a suitable technique for continuous and mass production of these valuable compounds with high efficiency for a short time (Ourmazdi and Chalabian 2006). Callus induction from plant tissues is influenced by several factors, such as genotype, explant type, growth regulators, culture medium, type of nutrients, environmental conditions as well as elicitors (Hasanloo et al. 2009). Moreover, elicitors' roles in culture conditions for boost the production of a diversity of metabolites have been confirmed (Zhao et al. 2005). Recent studies have shown that these inductions are highly depend on the alteration of physiological responses and the accumulation of phytoalexins under stress conditions (Baskaran et al. 2012). Generally, the application of various elicitors, like nano-titanium dioxide (nano- $\left.\mathrm{TiO}_{2}\right)$ and methyl jasmonate $(\mathrm{MeJa})$ with a concentration-dependent manner, is remarkably advisable to promote the generation and accumulation of phenolic compounds during the culture process (Ge and Wu 2005; Bahreini et al. 2015). Based on the literature, the nano- $\mathrm{TiO}_{2}$ effect on the induction and accumulation of phenolic compounds has been studied in different plant species, such as Salvia officinalis (Ghorbanpour 2015), Papaver somniferum (Khodayari et al. 2014), Aloe vera (Raei et al. 2014), and Foeniculum vulgare (Bahreini et al. 2015). It has also 
been proved that the production of phenolic compounds, especially rosmarinic acid, can be promoted after MeJa elicitation in Salvia virgata (Dowom et al. 2017), Salvia officinalis (Grzegorczyk and Wysokińska 2009), Salvia miltiorrhiza (Ge and Wu 2005) and Exacum affine Balf. f. ex (Skrzypczak-Pietraszek et al. 2014).

Up to the present time, very little information is available about secondary metabolites of $S$. tebesana as a traditional medicinal plant (Goldansaz et al. 2017; Eghbaliferiz et al. 2018; Fotovvat et al. 2018). Although Hemmati et al. (2020) has studied the effect of some growth hormones (BAP, 2,4-D, and NAA) on tissue culture and phenolic compounds accumulation of $S$. tebesana in vitro, there still is no report available regarding cell and tissue culture or the effect of elicitors on secondary metabolites of $S$. tebesana. This study was done for the first time (a) to create an efficient system to optimize the culture condition and hormonal composition for the large-scale production of callus, (b) to find the optimal concentration of nano- $\mathrm{TiO}_{2}$ and MeJa elicitors to enhance the level of phenolic secondary metabolites and antioxidant properties, and (c) to evaluate the content changes of RA and some individual flavonoids (Apigenin, Quercetin, and Rutin) in elicitor- treated calli.

\section{Materials And Methods}

\section{Plant material}

Plant collecting and in vitro growth condition was performed according to our previous research (Hemmati et al. 2020). The plant grown in Hoagland nutrient solution (Hoagland and Arnon 1950) was used as a source of apical meristem and leaf explants. For sterilization of explants, the samples rinsed 3 times with sterile distilled water, followed by immersing in $70 \%(\mathrm{v} / \mathrm{v})$ methanol (for 30 sec and once). Leaf explants were also plunged in $5 \%(\mathrm{v} / \mathrm{v})$ sodium hypochlorite (3 min and once). The final wash of both explants was done 3 times with sterile distilled water.

\section{Culture conditions and callus induction}

Because one of the aims of the present study was to assess the effect of elicitors on the best callus-inducing hormonal medium, some hormonal conditions related to Hemmati's study were nominated to evaluate the best conditions (Hemmati et al. 2020). Apical meristem and leaf explants were cultured on MS medium with different concentrations of $\operatorname{BAP}\left(0,0.5\right.$, and $\left.1 \mathrm{mg} \mathrm{L}^{-1}\right)$ and 2,4-D $(0,0.5,1$, and 1.5 $\left.\mathrm{mg} \mathrm{L}^{-1}\right)$. Three replications were considered for each treatment, and five explants were cultured in each jar. After 3 weeks of dark treatment, the samples were exposed to $16 \mathrm{~h}$ of light and $8 \mathrm{~h}$ of darkness at $25 \pm 2{ }^{\circ} \mathrm{C}$ for 4 weeks. Subculturing was performed in the 7th week with the same hormone concentrations. 90-day-old calli were harvested, and some morphological characteristics, including the percentage of callus induction and fresh and dry weight (FW and DW), were recorded. The percentage of callogenesis was calculated based on the following equation:

Rate of callogenesis $=$ number of explants with callus $/$ total number of explants used $\times 100$

The data obtained from the best growth rates of callus (the highest percentage of callogenesis and callus DW) was used to determine the best culture media.

\section{Preparation of elicitors}

Two elicitors, including nano- $\mathrm{TiO}_{2}\left(10,60\right.$, and $\left.120 \mathrm{mg} \mathrm{L}^{-1}\right)$ and MeJa $(50,100$, and $200 \mu \mathrm{M})$, were used. The stock of nano-TiO ${ }_{2}(\mathrm{stock}$ \#: US3490, US Research Nanomaterials, Inc.) was prepared by dissolving the specified amounts $(1.2 \mathrm{mg})$ of nano-TiO ${ }_{2}$ powder in $10 \mathrm{~mL}$ of sterile distilled water and dispersed using ultrasonic vibration by providing $40 \mathrm{kHz}$ wave signals at the temperature of $40{ }^{\circ} \mathrm{C}$ for 25 min (Ghorbanpour 2015). To prepare MeJa stock, a certain amount of it was dissolved in $96 \%$ ethanol (Wang et al. 2015). Both elicitors were filtered and sterilized using $0.22 \mu \mathrm{m}$ filters.

\section{Elicitation}

The culture of selected media was performed in a like manner to the first experiment till the 7th week. At the end of the 7th week and during the subculturing, elicitor solutions were added to basal culture media. The calluses were harvested after 10 days of elicitors' treatment, and the callus biomass (FW and DW) was estimated.

\section{Extraction for phytochemical analysis}


The 60-day-old calli were dried in an oven at $40{ }^{\circ} \mathrm{C}$ for $48 \mathrm{~h}$, and then, $80 \%(\mathrm{v} / \mathrm{v})$ methanol was added to the callus powder in a ratio of 1 to $100(\mathrm{w} / \mathrm{v})$. The obtained extracts were placed in an ultrasonic device (Parsonic 2600s, Japan) for 30 min at a temperature of $30^{\circ} \mathrm{C}$ and a frequency of $40 \mathrm{kHz}$. Then the extracts were filtered with Whatman paper (No. 1), and the solvent was evaporated under air condition. To prepare the final extract, the extract powder $(0.0015 \mathrm{~g})$ was dissolved in $5 \mathrm{~mL}$ of $80 \%(\mathrm{v} / \mathrm{v})$ methanol (Annegowda et al. 2012). This solution was used as a "methanolic extract" for all the phytochemical assays.

\section{Determination of total phenolic compounds}

The content of phenolics in elicitor-treated calli was assessed by the Folin-Ciocalteu method (Marinova et al. 2005). For this purpose, $2.5 \mathrm{~mL}$ of $10 \%(\mathrm{v} / \mathrm{v})$ folin was added to $100 \mu \mathrm{L}$ of "methanolic extract". After $5 \mathrm{~min}$ in the dark condition and room temperature, $2 \mathrm{~mL}$ of $7.5 \%(\mathrm{w} / \mathrm{v})$ sodium carbonate was added, and after $1.5 \mathrm{~h}$, the absorption was read by a spectrophotometer (Jasco7800, Germany) at $765 \mathrm{~nm}$. The content of phenolic compounds of any sample was calculated based on the standard curve of gallic acid equivalent (GAE) $\left(y=0.0032 x+0.0313, r^{2}=0.987\right)$, and the result was presented in terms of mg GAE per $100 \mathrm{~g} \mathrm{DW}$ of the callus sample.

\section{Determination of total O-diphenols content}

The reaction mixture was prepared by adding $2 \mathrm{~mL}$ of $50 \%(\mathrm{v} / \mathrm{v})$ aqueous methanol and $0.5 \mathrm{~mL}$ of $5 \%(\mathrm{w} / \mathrm{v}$ ) sodium molybdate dihydrate to $100 \mu \mathrm{L}$ of "methanolic extract". The samples were shaken for $15 \mathrm{~min}$ and exposed to darkness at room temperature. Finally, the light absorption of the samples was recorded at $370 \mathrm{~nm}$ (Carrasco-Pancorbo et al. 2005). The basis for calculating of total $O$ diphenols content was the gallic acid graph $\left(y=0.0042 x+0.0674, r^{2}=0.998\right)$, which was expressed as mg of GAE per $100 \mathrm{~g}$ DW of callus.

\section{Determination of phenolic acids content}

The content of phenolic acids was determined based on the Matkowski method (Matkowski 2008). Distilled water (1.25 mL), hydrogen chloride $(250 \mu \mathrm{L})$, Arnow's reagent [10\% (w/v) aqueous sodium molybdate and $10 \%(\mathrm{w} / \mathrm{v})$ aqueous sodium nitrite] $(250 \mu \mathrm{L})$ were added, respectively, to $250 \mu \mathrm{L}$ of "methanolic extract". After being kept in total darkness for $30 \mathrm{~min}\left(25 \pm 2{ }^{\circ} \mathrm{C}\right), 250 \mu \mathrm{L}$ of sodium hydroxide with $250 \mu \mathrm{L}$ of distilled water were added to the sample, and the absorbance was read at $490 \mathrm{~nm}$. The phenolic acid content was calculated based on the standard caffeic acid equivalent (CAE) graph $\left(y=0.0041 x+0.0258, r^{2}=0.983\right)$, and the result was presented in terms of mg of CAE per $100 \mathrm{~g}$ DW of callus.

\section{Determination of flavonoids content}

A valoum of $300 \mu \mathrm{L}$ of "methanolic extract" was mixed to $3.4 \mathrm{~mL}$ of $30 \%(\mathrm{v} / \mathrm{v})$ methanol. Then $150 \mu \mathrm{L}$ of $0.5 \mathrm{M}$ sodium nitrite and 150 $\mu \mathrm{L}$ of $0.3 \mathrm{M}$ aluminum chloride were added, respectively. After keeping the samples in the dark at room temperature for $5 \mathrm{~min}, 1 \mathrm{~mL}$ of 1 $M$ sodium hydroxide was added, and the absorbance was recorded at $510 \mathrm{~nm}$ (Zhishen et al. 1999). Catechin (CAT) equivalent was used to prepare the standard curve $\left(y=0.0018 x+0.0106, r^{2}=0.989\right)$, and the result was calculated in mg of CATE per $100 \mathrm{~g}$ DW of callus sample.

\section{Determination of flavone and flavonol content}

Quercetin equivalent (QE) was used to make the calibration curve for this assay $\left(y=0.0022 x-0.007, r^{2}=0.982\right)$. It was added $250 \mu \mathrm{L}$ of "methanolic extract" to $50 \mu \mathrm{L}$ of $10 \%(\mathrm{w} / \mathrm{v})$ aluminum chloride and $50 \mu \mathrm{L}$ of $1 \mathrm{M}$ potassium acetate. Then, $750 \mu \mathrm{L}$ of $80 \%$ methanol $(\mathrm{v} / \mathrm{v})$ and $1.4 \mathrm{~mL}$ of distilled water were added till the final volume reached $2.5 \mathrm{~mL}$. After $30 \mathrm{~min}$ at room temperature, the absorbance was read at $415 \mathrm{~nm}$ (Kosalec et al. 2004). Using the standard curve line equation obtained from quercetin, the amount of flavone and flavonol in the extract was calculated and expressed as mg QE per $100 \mathrm{~g} \mathrm{DW}$ of callus sample.

\section{Determination of total proanthocyanidins content}

In this step, $250 \mu \mathrm{L}$ of the diluted extract was added to pure methanol $(1 \mathrm{~mL})$ and then, to $3 \mathrm{~mL}$ of $1 \%(\mathrm{w} / \mathrm{v})$ vanillin. After vortex (WiseMix, Korea) for $30 \mathrm{sec}, 2.5 \mathrm{~mL}$ of $9 \mathrm{~N}$ methanolic sulfuric acid was added. The samples were placed in Ben-Marie (Kavoosh Mega, Iran) for $15 \mathrm{~min}$ at $38{ }^{\circ} \mathrm{C}$ (in the dark). Finally, the optical absorption of the reaction mixture was recorded at $500 \mathrm{~nm}$ (Sun et al. 1998). Total proanthocyanidin content was defined with the standard curve of catechin solution $\left(y=0.001 x+0.0653, r^{2}=0.939\right)$ and expressed as mg of CATE per $100 \mathrm{~g} \mathrm{DW}$ of callus sample. 
According to the method described by Öztürk et al. (2010), the concentration of rosmarinic acid in the samples was calculated based on the rosmarinic acid complex with zirconium ions $\left(\mathrm{Zr}^{4+}\right)$ by spectrophotometer assay. $920 \mu \mathrm{L}$ of pure ethanol was added to $40 \mu \mathrm{L}$ of the extract, and the final volume was increased to $1 \mathrm{~mL}$ by adding $40 \mu \mathrm{L}$ of $0.5 \mathrm{M}$ zirconium chloride. About 5 min following the addition of the zirconium salt solution, the absorbance of the sample was measured at $362 \mathrm{~nm}$. Using the obtained equation $\left(y=0.014 x+0.024, r^{2}=\right.$ 0.991) from the standard curve of RA, the amount of rosmarinic acid was calculated as mg of RA per $100 \mathrm{~g}$ of DW of callus sample.

\section{Antioxidant activity}

\section{DPPH scavenging activity assay}

As described by de Torre et al. (2019), $100 \mu \mathrm{L}$ of "methanolic extract" and $100 \mu \mathrm{L}$ of methanolic DPPH solution (0.2 mM) were poured into each well of the 96 -well plate, respectively. The plate was incubated in the dark at $25 \pm 2{ }^{\circ} \mathrm{C}$ for half an hour, and then, its absorbance was read at $490 \mathrm{~nm}$ by the Elisa Reader (Gentaur ST2100, America). The antioxidant capacity was calculated in terms of Inhibitory concentration ( $\mathrm{IC}_{50}$; effective concentration of sample with $50 \%$ DPPH inhibitory capacity), and in comparison with the antioxidant capacity of ascorbic acid (as positive control) at the same concentrations of the sample. To calculate IC, the following equation was used:

$I C \%=[1-(A S-A B) /(A C-A B)] \times 100$

In the above equation, AS represents the adsorption of the extracted sample, AB represents the adsorption of the blank sample ( $100 \mu \mathrm{L}$ of extract and $100 \mu \mathrm{L}$ of pure methanol), and $\mathrm{AC}$ represents the adsorption of the control sample (100 $\mu \mathrm{L}$ of pure methanol and $100 \mu \mathrm{L}$ of DPPH solution).

\section{Ferric Reducing Antioxidant Power (FRAP) assay}

The reduction ability of callus extract was analyzed using FRAP assay according to Li et al. (2017) with a minor modification. For this purpose, FRAP reagent was prepared by adding acetate buffer (300 mM; pH=3.6), $10 \mathrm{mM}$ 2,4,6-tri (2-pyridyl)-1,3,5-triazine (TPTZ) solution in $40 \mathrm{mM} \mathrm{HCL}$, and $20 \mathrm{Mm} \mathrm{FeCl}_{3} \cdot 6 \mathrm{H}_{2} \mathrm{O}$ solution in a volume ratio of $10: 1: 1$. The "methanolic extract" of callus $(20 \mu \mathrm{L})$ was mixed with $130 \mu \mathrm{L}$ of FRAP solution and incubated in the dark for $30 \mathrm{~min}$. The absorbance of reaction mixture was assayed through the ELISA system at $630 \mathrm{~nm}$. Ferrous sulfate II $\left(\mathrm{FeSO}_{4}\right)$ was applied to produce a standard curve $\left(y=0.0165 x+1.323, r^{2}=0.908\right)$. The results were expressed in $\mathrm{mg}$ of $\mathrm{Fe}^{+2}$ per $100 \mathrm{~g} \mathrm{DW}$ of callus sample.

\section{LC-MS analysis}

\section{Callus extraction}

For LC-MC analysis, both explant-derived calli with the highest content of flavonoids, flavone and flavonols, were selected. $0.25 \mathrm{gr}$ of dry callus powder was dissolved in $2.5 \mathrm{~mL}$ of HPLC grade methanol. After $2 \mathrm{~h}$ using an ultrasonic bath at a temperature of $30^{\circ} \mathrm{C}$ and a frequency of $40 \mathrm{kHz}$, the solution was filtered through a $45 \mu \mathrm{m}$ filter, and the solvent was evaporated under air condition (Skerget et al. 2005). For flavonoid extraction of each dry sample, the extractive solution ( $75 \%$ methanol $/ 0,1 \%$ formic acid) and continuing process were done according to the method described by Gómez et al. (2018).

\section{LC-MS analysis of specific individual flavonoids}

HPLC separation was carried out using the mobile phase containing solvent A and B in gradient. Mobile phase A consisted of $0.1 \%$ formic acid in acetonitrile $(\mathrm{v} / \mathrm{v})$, and mobile phase $B$ consisted of $0.1 \%$ formic acid in $\mathrm{H} 2 \mathrm{O}(\mathrm{v} / \mathrm{v})$. The volume of injection was $5 \mu \mathrm{L}$ in all samples. Chromatographic separation was performed on an Atlantis T3-C18 $3 \mu, 2.1 \times 150 \mathrm{~mm}$ column at a flow rate of $0.15 \mathrm{~mL} / \mathrm{min}$. The column oven temperature was set at $40^{\circ} \mathrm{C}$. Mass spectra were acquired in the positive ion mode $(\mathrm{ESI}+)$. The following parameters were used in all experiments: cone voltage, $30 \mathrm{~V}$; capillary voltage, 4kV; extractor, $2 \mathrm{~V}$; RF lens, $0.2 \mathrm{~V}$; collision energy, $30 \mathrm{eV}$; gas nebulizer, N2 (grade 5); flow gas, $200 \mathrm{~L} / \mathrm{h}$; source temperature, $120^{\circ} \mathrm{C}$; desolation temperature, $300^{\circ} \mathrm{C}$. A Waters Alliance $2695 \mathrm{HPLC}-$ Micromass Quattro micro API Mass Spectrometer was used for the analysis. The reference substances of flavone (Apigenin) and flavonols (Quercetin and Rutin) were obtained from Sigma-Aldrich (St. Luis, MO, USA).

\section{Statistical analysis}




\section{Results}

\section{Callus induction of apical meristem and leaf explants}

The results showed that internal hormones significantly affected the callus induction at $p \leq 0.01$ (Duncan's multiple range test). The individually adding of BAP and 2,4-D are shown that they were not successful for callogenesis. Results obtained for 2,4-D alone were zero, or near-zero for callus formation of both explants, while apical meristem in the media supplemented with BAP alone was more desired to branch. However, the simultaneous use of these hormones and their interaction significantly increased the callus induction (Table 1). For apical meristem explant, the best callus induction rate with the highest fresh and dry weight was obtained from the media with "BAP $0.5+2,4-\mathrm{D}_{0.5}$ " and "BAP ${ }_{1}+2,4-\mathrm{D}_{1}$ " $\mathrm{mg} \mathrm{L}^{-1}$, while in the case of the leaf explant, the highest callogenesis rate, fresh and dry

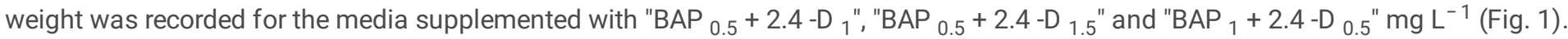
In terms of appearance, all the calli were also observed in friable form with yellow, light, or dark green colors. 
Table 1

Callus induction of apical meristem and leaf explants of $S$. tebesana on MS medium supplemented with different concentrations of BAP and 2,4-D.

\begin{tabular}{|c|c|c|c|c|}
\hline Explant type & Hormone treatment $\left(\mathrm{mg} \mathrm{L}^{-1}\right)$ & $\%$ of Callus induction & Fresh weight (g) & Dry weight (g) \\
\hline \multirow[t]{12}{*}{ Apical meristem } & Control 1: "BAP 0 + 2,4-D $0 "$ & $0^{d}$ & $0.00 \pm 0.00^{\mathrm{e}}$ & $0.00 \pm 0.00^{\mathrm{e}}$ \\
\hline & "BAP $0.5+2,4-D_{0} "$ & $6.66^{\text {de }}$ & $0.63 \pm 0.62^{e}$ & $0.05 \pm 0.05 \mathrm{de}$ \\
\hline & $" \mathrm{BAP}_{1}+2,4-\mathrm{D}_{0} "$ & 6.66 de & $0.64 \pm 0.64^{e}$ & $0.05 \pm 0.05$ de \\
\hline & "BAP $00+2,4-D_{0.5}$ & $6.66 \mathrm{de}$ & $0.62 \pm 0.62^{e}$ & $0.04 \pm 0.04$ de \\
\hline & "BAP $0.5+2,4-D_{0.5}$ & $93.33^{\text {a }}$ & $6.32 \pm 0.26^{a}$ & $0.44 \pm 0.04^{a}$ \\
\hline & "BAP $1+2,4-D_{0.5}$ & $73.33^{a b}$ & $3.20 \pm 0.42^{c}$ & $0.19 \pm 0.01^{b c d}$ \\
\hline & $" \mathrm{BAP}_{0}+2,4-\mathrm{D}_{1} "$ & 13.33 de & $1.19 \pm 0.59$ de & $0.10 \pm 0.05^{\mathrm{cde}}$ \\
\hline & "BAP $0.5+2,4-D_{1} "$ & $53.33^{b c}$ & $4.66 \pm 0.39 b$ & $0.28 \pm 0.03^{b}$ \\
\hline & $" \mathrm{BAP}_{1}+2,4-\mathrm{D}_{1} "$ & $100^{\mathrm{a}}$ & $5.95 \pm 0.08$ a & $0.55 \pm 0.03$ a \\
\hline & "BAP 0 + 2,4-D $1.5 "$ & $6.66^{\text {de }}$ & $0.47 \pm 0.47^{\mathrm{e}}$ & $0.04 \pm 0.04 \mathrm{de}$ \\
\hline & "BAP $0.5+2,4-D_{1.5}$ & $40^{\mathrm{cd}}$ & $2.30 \pm 0.13^{c d}$ & $0.14 \pm 0.01$ bcde \\
\hline & BAP $_{1}+2,4-\mathrm{D}_{1.5}$ & $50 \mathrm{bc}$ & $3.24 \pm 0.53^{c}$ & $0.22 \pm 0.05^{b c}$ \\
\hline \multirow[t]{12}{*}{ Leaf } & Control 2: "BAP $0+2,4-D_{0}$ " & $0^{d}$ & $0.00 \pm 0.00^{e}$ & $0.00 \pm 0.00^{c}$ \\
\hline & "BAP $0.5+2,4-D_{0}$ & $6.66^{d}$ & $0.25 \pm 0.25$ de & $0.01 \pm 0.01^{c}$ \\
\hline & $" \mathrm{BAP}_{1}+2,4-\mathrm{D}_{0} "$ & $6.66^{d}$ & $0.21 \pm 0.21 \mathrm{de}$ & $0.01 \pm 0.01^{c}$ \\
\hline & "BAP $00+2,4-D_{0.5}$ & $13.33^{d}$ & $0.37 \pm 0.18$ de & $0.02 \pm 0.01^{c}$ \\
\hline & "BAP $0.5+2,4-D_{0.5}$ & $40^{c}$ & $1.73 \pm 0.66^{\mathrm{cd}}$ & $0.11 \pm 0.04^{b}$ \\
\hline & "BAP 1 + 2,4-D $0.5 "$ & $86.66^{a b}$ & $2.92 \pm 0.31^{c}$ & $0.16 \pm 0.03^{b}$ \\
\hline & $" \mathrm{BAP}_{0}+2,4-\mathrm{D}_{1} "$ & $6.66^{d}$ & $0.20 \pm 0.20$ de & $0.01 \pm 0.01^{c}$ \\
\hline & "BAP $0.5+2,4-D_{1} "$ & $93.33^{a}$ & $6.39 \pm 1.02^{b}$ & $0.36+ \pm 0.02^{a}$ \\
\hline & $" \mathrm{BAP}_{1}+2,4-\mathrm{D}_{1} "$ & $66.66^{b}$ & $2.51 \pm 0.18^{c}$ & $0.15 \pm 0.01^{b}$ \\
\hline & "BAP 0 + 2,4-D $1.5 "$ & $6.66^{d}$ & $0.24 \pm 0.24 \mathrm{de}$ & $0.01 \pm 0.01^{c}$ \\
\hline & BAP $_{0.5}+2,4-D_{1.5}$ & $93.33^{a}$ & $8.20 \pm 0.83^{a}$ & $0.33 \pm 0.03^{a}$ \\
\hline & "BAP 1 + 2,4-D $1.5 "$ & $66.66^{b}$ & $2.40 \pm 0.31^{c}$ & $0.17 \pm 0.03^{b}$ \\
\hline
\end{tabular}

\section{Effect of elicitors on polyphenols content of apical meristem-derived callus}

The content of different phenolic compounds in apical meristem-derived calli was significantly affected $(P \leq 0.01)$ by elicitor type and hormonal treatment. As a general result, it can be said that most polyphenolic compounds were observed in the samples on basal media with "BAP $0.5+2,4-\mathrm{D}_{0.5}$ " $\mathrm{mg} \mathrm{L}^{-1}$. The highest content of total phenols (1074.07 $\left.\pm 47.59 \mathrm{mg} 100 \mathrm{~g} \mathrm{~g}^{-1} \mathrm{DW}\right)$ and rosmarinic acid

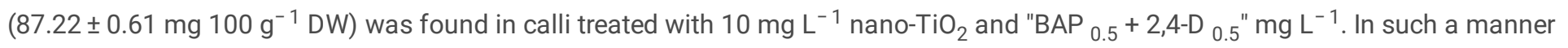
that the phenol content of callus on this medium was more than double that of control in the same hormonal treatment. Regarding total 
O-diphenol, flavone, and flavonol contents, the treatment with $10 \mathrm{mg} \mathrm{L}^{-1}$ nano- $\mathrm{TiO}_{2}$ and $50 \mu \mathrm{M} \mathrm{MeJa}$ on the media containing "BAP 0.5 $+2,4-\mathrm{D}_{0.5} \mathrm{"} \mathrm{mg} \mathrm{L}^{-1}$ led to the highest levels of these compounds in comparison with other samples. Additionally, $50 \mu \mathrm{M}$ MeJa-treated

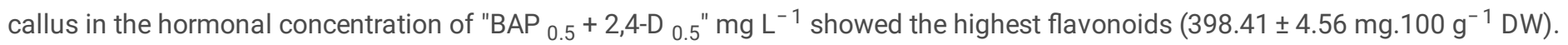
Concerning the content of phenolic acids and proanthocyanidins, the result showed that $10 \mathrm{mg} \mathrm{L}^{-1}$ nano- $\mathrm{TiO}_{2}$ and $50 \mu \mathrm{M} \mathrm{MeJa}$ treatments on calli generated on "BAP $0.5+2,4-\mathrm{D}_{0.5}$ " $\mathrm{mg} \mathrm{L}^{-1}$ caused the highest content of these compounds (Table 2). 
Table 2

Effect of nano- $\mathrm{TiO}_{2}$ and MeJa elicitors as well as hormonal combination on phenolic derivatives contents in apical meristem-derived calli of S. tebesana.

\begin{tabular}{|c|c|c|c|c|c|c|c|c|c|}
\hline $\begin{array}{l}\text { Explant } \\
\text { type }\end{array}$ & $\begin{array}{l}\text { Hormone } \\
\text { treatment }\end{array}$ & $\begin{array}{l}\text { Elicitor } \\
\text { type }\end{array}$ & $\begin{array}{l}\begin{array}{l}\text { Total } \\
\text { phenolics }\end{array} \\
\text { mg GAE } \\
100 \mathrm{~g}^{-1} \\
\text { DW }\end{array}$ & $\begin{array}{l}\begin{array}{l}\text { Total } 0 \\
\text { di } \\
\text { phenols }\end{array} \\
\text { mg } \\
\text { GAE } \\
100 \mathrm{~g}^{-1} \\
\text { DW }\end{array}$ & $\begin{array}{l}\begin{array}{l}\text { Total } \\
\text { phenolic } \\
\text { acids }\end{array} \\
\mathrm{mg} \mathrm{CAE} \\
100 \mathrm{~g}^{-1} \\
\text { DW }\end{array}$ & $\begin{array}{l}\text { Total } \\
\text { flavonoids } \\
\text { mg CATE } \\
100 \mathrm{~g}^{-1} \\
\text { DW }\end{array}$ & $\begin{array}{l}\text { Total } \\
\text { flavone } \\
\& \\
\text { flavonol } \\
\text { mg QE } \\
100 \mathrm{~g}^{-1} \\
\text { DW }\end{array}$ & $\begin{array}{l}\text { Proanthocyanidins } \\
\text { mg CATE } 100 \mathrm{~g}^{-1} \\
\text { DW }\end{array}$ & $\begin{array}{l}\begin{array}{l}\text { Rosmarinic } \\
\text { acid }\end{array} \\
\mathrm{mg} 100 \mathrm{~g}^{-} \\
{ }^{-} \mathrm{DW}\end{array}$ \\
\hline \multirow[t]{12}{*}{$\begin{array}{l}\text { Apical } \\
\text { meristem }\end{array}$} & \multirow[t]{7}{*}{$\begin{array}{l}\mathrm{BAP}_{0.5}+ \\
2,4-\mathrm{D}_{0.5} \\
\mathrm{mg} \mathrm{L}^{-1}\end{array}$} & $\begin{array}{l}\text { Control } \\
1(0)\end{array}$ & $\begin{array}{l}427.20 \pm \\
22.11^{\mathrm{g}}\end{array}$ & $\begin{array}{l}123.01 \\
\pm 1.70 \mathrm{~g}\end{array}$ & $\begin{array}{l}118.84 \\
\pm 1.14 \text { ef }\end{array}$ & $\begin{array}{l}207.43 \pm \\
7.20 e^{e}\end{array}$ & $\begin{array}{l}117.17 \\
\pm 5.79 \\
\text { gh }\end{array}$ & $80.95 \pm 1.65^{\mathrm{e}}$ & $\begin{array}{l}37.27 \pm \\
0.52^{i}\end{array}$ \\
\hline & & $\begin{array}{l}10 \mathrm{mg} \\
\mathrm{L}^{-1} \\
\text { nano- } \\
\mathrm{TiO}_{2}\end{array}$ & $\begin{array}{l}1074.07 \\
\pm 47.59 \text { a }\end{array}$ & $\begin{array}{l}228.96 \\
\pm 4.88\end{array}$ & $\begin{array}{l}211.74 \\
\pm 1.67^{a}\end{array}$ & $\begin{array}{l}341.63 \pm \\
10.59^{c}\end{array}$ & $\begin{array}{l}226.15 \\
\pm 3.32^{a}\end{array}$ & $123.86 \pm 1.59 a$ & $\begin{array}{l}87.22 \pm \\
0.61^{a}\end{array}$ \\
\hline & & $\begin{array}{l}60 \mathrm{mg} \\
\mathrm{L}^{-1} \\
\text { nano- } \\
\mathrm{TiO}_{2}\end{array}$ & $\begin{array}{l}762.72^{ \pm} \\
36.82^{c}\end{array}$ & $\begin{array}{l}194.78 \\
\pm 9.38^{c}\end{array}$ & $\begin{array}{l}173.31 \\
\pm 2.98^{c}\end{array}$ & $\begin{array}{l}304.25 \pm \\
1.48^{d}\end{array}$ & $\begin{array}{l}181.18 \\
\pm 3.46^{c}\end{array}$ & $106.16 \pm 4.25^{c}$ & $\begin{array}{l}66.23 \pm \\
0.55^{d}\end{array}$ \\
\hline & & $\begin{array}{l}120 \\
\mathrm{mg} \mathrm{L}^{-} \\
{ }^{1} \mathrm{nno}^{-} \\
\mathrm{TiO}_{2}\end{array}$ & $\begin{array}{l}690.40 \pm \\
15.04 \mathrm{~d}\end{array}$ & $\begin{array}{l}179.51 \\
\pm 1.06^{d}\end{array}$ & $\begin{array}{l}142.67 \\
\pm 0.97 \mathrm{~d}\end{array}$ & $\begin{array}{l}280.77 \pm \\
8.20 \text { de }\end{array}$ & $\begin{array}{l}143.07 \\
\pm 4.57 \\
\text { de }\end{array}$ & $104.44 \pm 3.97^{c}$ & $\begin{array}{l}58.30 \pm \\
0.56^{\mathrm{e}}\end{array}$ \\
\hline & & $\begin{array}{l}50 \mu \mathrm{M} \\
\mathrm{MeJa}\end{array}$ & $\begin{array}{l}643.30 \pm \\
8.91 \text { de }\end{array}$ & $\begin{array}{l}230.95 \\
\pm 3.39^{a}\end{array}$ & $\begin{array}{l}213.44 \\
\pm 2.24^{\mathrm{a}}\end{array}$ & $\begin{array}{l}472.41 \pm \\
15.91^{\mathrm{a}}\end{array}$ & $\begin{array}{l}200.30 \\
\pm 3.70^{b}\end{array}$ & $126.94 \pm 0.47^{a}$ & $\begin{array}{l}65.17 \pm \\
0.54^{d}\end{array}$ \\
\hline & & $\begin{array}{l}100 \\
\mu \mathrm{M} \\
\text { MeJa }\end{array}$ & $\begin{array}{l}40803 \pm \\
4.89 \mathrm{~g}\end{array}$ & $\begin{array}{l}194.99 \\
\pm 2.07^{c}\end{array}$ & $\begin{array}{l}178.87 \\
\pm 5.00 \mathrm{bc}\end{array}$ & $\begin{array}{l}304.97 \pm \\
8.80^{d}\end{array}$ & $\begin{array}{l}148.10 \\
\pm 3.66^{d}\end{array}$ & $112.32 \pm 1.16^{b}$ & $\begin{array}{l}55.19 \pm \\
0.63^{f}\end{array}$ \\
\hline & & $\begin{array}{l}200 \\
\mu \mathrm{M} \\
\mathrm{MeJa}\end{array}$ & $\begin{array}{l}330.07 \pm \\
7.48^{\mathrm{h}}\end{array}$ & $\begin{array}{l}209.33 \\
\pm 3.00^{b}\end{array}$ & $\begin{array}{l}186.85 \\
\pm 2.21^{b}\end{array}$ & $\begin{array}{l}258.28 \pm \\
3.84^{\mathrm{e}}\end{array}$ & $\begin{array}{l}115.11 \\
\pm 5.86 \\
\text { gh }\end{array}$ & $105.14 \pm 0.71^{c}$ & $\begin{array}{l}37.29 \pm \\
0.57^{i}\end{array}$ \\
\hline & \multirow{5}{*}{$\begin{array}{l}\mathrm{BAP}_{1}+ \\
2,4-\mathrm{D}_{1} \\
\mathrm{mg} \mathrm{L}^{-1}\end{array}$} & $\begin{array}{l}\text { Control } \\
2(0)\end{array}$ & $\begin{array}{l}401.1 \pm \\
9.99 \mathrm{~g}\end{array}$ & $\begin{array}{l}105.25 \\
\pm 3.43^{h}\end{array}$ & $\begin{array}{l}107.81 \\
\pm 6.96 \mathrm{fg}\end{array}$ & $\begin{array}{l}183.56 \pm \\
7.36^{\mathrm{g}}\end{array}$ & $\begin{array}{l}105.77 \\
\pm 2.80^{h}\end{array}$ & $48.59 \pm 1.55^{\mathrm{g}}$ & $\begin{array}{l}35.82 \pm \\
0.34^{i}\end{array}$ \\
\hline & & $\begin{array}{l}10 \mathrm{mg} \\
\mathrm{L}^{-1} \\
\text { nano- } \\
\mathrm{TiO}_{2}\end{array}$ & $\begin{array}{l}867.76 \pm \\
6.81^{b}\end{array}$ & $\begin{array}{l}206.10 \\
\pm 2.96 \\
b c\end{array}$ & $\begin{array}{l}181.95 \\
\pm 2.54 \text { bc }\end{array}$ & $\begin{array}{l}298.13 \pm \\
2.88^{d}\end{array}$ & $\begin{array}{l}203.70 \\
\pm 2.92^{b}\end{array}$ & $89.94 \pm 2.21^{d}$ & $\begin{array}{l}79.09 \pm \\
0.53^{b}\end{array}$ \\
\hline & & $\begin{array}{l}60 \mathrm{mg} \\
\mathrm{L}^{-1} \\
\text { nano- } \\
\mathrm{TiO}_{2}\end{array}$ & $\begin{array}{l}630.89 \pm \\
10.74 \mathrm{e}^{\mathrm{e}}\end{array}$ & $\begin{array}{l}141.52 \\
\pm 4.84^{f}\end{array}$ & $\begin{array}{l}138.43 \\
\pm 4.03^{d}\end{array}$ & $\begin{array}{l}226.67 \pm \\
11.59^{f}\end{array}$ & $\begin{array}{l}132.09 \\
\pm 5.42 \text { ef }\end{array}$ & $55.95 \pm 1.52^{f}$ & $\begin{array}{l}55.14 \pm \\
0.63^{f}\end{array}$ \\
\hline & & $\begin{array}{l}120 \\
\mathrm{mg} \mathrm{L}^{-} \\
1 \text { nano- } \\
\mathrm{TiO}_{2}\end{array}$ & $\begin{array}{l}554.92 \pm \\
12.33^{f}\end{array}$ & $\begin{array}{l}130.82 \\
\pm 4.41 \\
\mathrm{fg}\end{array}$ & $\begin{array}{l}129.79 \\
\pm 4.80 \mathrm{de}\end{array}$ & $\begin{array}{l}265.06 \pm \\
3.41^{\mathrm{e}}\end{array}$ & $\begin{array}{l}122.56 \\
\pm 2.65 \\
\mathrm{fg}\end{array}$ & $48.90 \pm 1.75^{g}$ & $\begin{array}{l}53.24 \pm \\
0.64 \mathrm{fg}\end{array}$ \\
\hline & & $\begin{array}{l}50 \mu \mathrm{M} \\
\mathrm{MeJa}\end{array}$ & $\begin{array}{l}686.95 \pm \\
3.33^{d e}\end{array}$ & $\begin{array}{l}207.56 \\
\pm 4.45^{b}\end{array}$ & $\begin{array}{l}203.60 \\
\pm 2.73^{a}\end{array}$ & $\begin{array}{l}398.41 \pm \\
4.56^{b}\end{array}$ & $\begin{array}{l}221.11 \\
\pm 2.47^{a}\end{array}$ & $110.31 \pm 1.05 \mathrm{bc}$ & $\begin{array}{l}76.59 \pm \\
0.86^{c}\end{array}$ \\
\hline
\end{tabular}

Each value represents mean \pm SE. Within a column, means followed by the same letter are not significantly different $(P \leq 0.01)$ according to Duncan's Multiple Range Test. 


\begin{tabular}{|c|c|c|c|c|c|c|c|c|c|}
\hline $\begin{array}{l}\text { Explant } \\
\text { type }\end{array}$ & $\begin{array}{l}\text { Hormone } \\
\text { treatment }\end{array}$ & $\begin{array}{l}\text { Elicitor } \\
\text { type }\end{array}$ & $\begin{array}{l}\begin{array}{l}\text { Total } \\
\text { phenolics }\end{array} \\
\text { mg GAE } \\
100 \mathrm{~g}^{-1} \\
\text { DW }\end{array}$ & $\begin{array}{l}\text { Total } 0 \\
\text { di } \\
\text { phenols } \\
\text { mg } \\
\text { GAE } \\
100 g^{-1} \\
\text { DW }\end{array}$ & $\begin{array}{l}\text { Total } \\
\text { phenolic } \\
\text { acids } \\
\text { mg CAE } \\
100 \mathrm{~g}^{-1} \\
\text { DW }\end{array}$ & $\begin{array}{l}\begin{array}{l}\text { Total } \\
\text { flavonoids }\end{array} \\
\text { mg CATE } \\
100 \mathrm{~g}^{-1} \\
\text { DW }\end{array}$ & $\begin{array}{l}\text { Total } \\
\text { flavone } \\
\& \\
\text { flavonol } \\
\text { mg QE } \\
100 \mathrm{~g}^{-1} \\
\text { DW }\end{array}$ & $\begin{array}{l}\text { Proanthocyanidins } \\
\text { mg CATE } 100 \mathrm{~g}^{-1} \\
\text { DW }\end{array}$ & $\begin{array}{l}\begin{array}{l}\text { Rosmarinic } \\
\text { acid }\end{array} \\
\mathrm{mg} 100 \mathrm{~g}^{-} \\
{ }^{1} \mathrm{DW}\end{array}$ \\
\hline & & $\begin{array}{l}100 \\
\mu \mathrm{M} \\
\text { MeJa }\end{array}$ & $\begin{array}{l}522.28 \pm \\
5.54^{f}\end{array}$ & $\begin{array}{l}180.43 \\
\pm 2.24\end{array}$ & $\begin{array}{l}98.42 \pm \\
4.15^{\mathrm{g}}\end{array}$ & $\begin{array}{l}336.98 \pm \\
5.16^{c}\end{array}$ & $\begin{array}{l}130.25 \\
\pm 1.81^{\mathrm{f}}\end{array}$ & $92.77 \pm 1.42^{d}$ & $\begin{array}{l}52.56 \pm \\
1.24{ }^{g}\end{array}$ \\
\hline & & $\begin{array}{l}200 \\
\mu \mathrm{M} \\
\mathrm{MeJa}\end{array}$ & $\begin{array}{l}377.23 \pm \\
6.54 \mathrm{gh}\end{array}$ & $\begin{array}{l}164.10 \\
\pm 1.30^{\mathrm{e}}\end{array}$ & $\begin{array}{l}134.02 \\
\pm 9.08^{d}\end{array}$ & $\begin{array}{l}265.69 \pm \\
5.46^{e}\end{array}$ & $\begin{array}{l}148.45 \\
\pm 1.33^{d}\end{array}$ & $83.61 \pm 0.66^{\mathrm{e}}$ & $\begin{array}{l}39.96 \pm \\
0.86^{h}\end{array}$ \\
\hline
\end{tabular}

\section{Effect of elicitors on polyphenols content of leaf derived callus}

Taking into account the changes of all analyzed compounds in leaf-derived calli, the highest amount of these compounds was observed in media with MS salts and "BAP $0.5+2,4-\mathrm{D}_{1}$ " $\mathrm{mg} \mathrm{L}^{-1}$ hormones. Total phenolic compound in calluses was found to range between $1392.14 \pm 37.77$ and $292.56 \pm 9.42 \mathrm{mg} 100 \mathrm{~g}^{-1} \mathrm{DW}$. The highest concentration of phenolics was measured in the callus treated with $60 \mathrm{mg} \mathrm{L}^{-1}$ nano- $\mathrm{TiO}_{2}$ on the medium with "BAP ${ }_{0.5}+2,4-\mathrm{D}_{1}$ " $\mathrm{mg} \mathrm{L}^{-1}$ hormonal treatment, which was about 3 times more than the amount (504.53 $\pm 42.47 \mathrm{mg} 100 \mathrm{~g}^{-1} \mathrm{DW}$ ) recorded in the control sample. Exposure to $60 \mathrm{mg} \mathrm{L}^{-1}$ nano- $\mathrm{TiO}_{2}$ in the medium supplemented with "BAP $0.5+2,4-\mathrm{D}_{1}$ " $\mathrm{mg} \mathrm{L}^{-1}$ induced the most increment in total $O$-diphenols, phenolic acids, proanthocyanidins, and rosmarinic acid contents, which were $236.74 \pm 9.58,341.74 \pm 9.71,244.50 \pm 4.35$, and $113.39 \pm 2.08 \mathrm{mg} .100 \mathrm{~g} \mathrm{~g}^{-1}$ DW callus, respectively. However, almost double the content of flavonoids than the control was observed when the lowest concentration of MeJa treatment, 50 $\mu \mathrm{M}$, was applied to the medium with "BAP $0.5+2,4-\mathrm{D}_{1}$ " $\mathrm{mg} \mathrm{L}^{-1}$. For all media, effective concentrations of treatments to increase the amounts of flavone and flavonol in calli were $60 \mathrm{mg} \mathrm{L}^{-1}$ nano- $\mathrm{TiO}_{2}$ and $50 \mu \mathrm{M} \mathrm{MeJa} \mathrm{(Table} \mathrm{3).}$ 
Table 3

Effect of nano-TiO ${ }_{2}$ and MeJa elicitors as well as hormonal combination on phenolic derivatives contents in leaf-derived calli of $S$. tebesana.

\begin{tabular}{|c|c|c|c|c|c|c|c|c|c|}
\hline $\begin{array}{l}\text { Explant } \\
\text { type }\end{array}$ & $\begin{array}{l}\text { Hormone } \\
\text { treatment }\end{array}$ & $\begin{array}{l}\text { Elicitor } \\
\text { type }\end{array}$ & $\begin{array}{l}\text { Phenolics } \\
\text { content } \\
\text { mg GAE } \\
100 \mathrm{~g}^{-1} \\
\text { DW }\end{array}$ & $\begin{array}{l}\begin{array}{l}\text { Total } O \\
\text { di } \\
\text { phenols }\end{array} \\
\text { mg GAE } \\
100 \mathrm{~g}^{-1} \\
\text { DW }\end{array}$ & $\begin{array}{l}\text { Total } \\
\text { phenolic } \\
\text { acids } \\
\text { mg CAE } \\
100 \mathrm{~g}^{-1} \\
\text { DW }\end{array}$ & $\begin{array}{l}\text { Total } \\
\text { flavonoids } \\
\text { mg CATE } \\
100 \mathrm{~g}^{-1} \\
\text { DW }\end{array}$ & $\begin{array}{l}\text { Total } \\
\text { flavone } \\
\& \\
\text { flavonol } \\
\mathrm{mg} \mathrm{QE} \\
100 \mathrm{~g}^{-1} \\
\text { DW }\end{array}$ & $\begin{array}{l}\text { Proanthocyanidins } \\
\text { mg CATE } 100 \mathrm{~g}^{-1} \\
\text { DW }\end{array}$ & $\begin{array}{l}\begin{array}{l}\text { Rosmarinic } \\
\text { acid }\end{array} \\
\mathrm{mg} 100 \mathrm{~g}^{-} \\
{ }^{1} \mathrm{DW}\end{array}$ \\
\hline \multirow[t]{13}{*}{ Leaf } & \multirow[t]{7}{*}{$\begin{array}{l}\mathrm{BAP}_{0.5}+ \\
2,4-\mathrm{D}_{1} \\
\mathrm{mg} \mathrm{L}^{-1}\end{array}$} & $\begin{array}{l}\text { Control } \\
1(0)\end{array}$ & $\begin{array}{l}504.53 \pm \\
42.47 \mathrm{ghi}\end{array}$ & $\begin{array}{l}127.35 \\
\pm 9.38 \\
\text { efg }\end{array}$ & $\begin{array}{l}160.03 \\
\pm 11.39 \\
\mathrm{e}\end{array}$ & $\begin{array}{l}195.22 \pm \\
10.50^{\mathrm{gh}}\end{array}$ & $\begin{array}{l}112.19 \\
\pm 2.79 \mathrm{ij}\end{array}$ & $117.62 \pm 5.49^{k}$ & $\begin{array}{l}43.15 \pm \\
0.56^{k}\end{array}$ \\
\hline & & $\begin{array}{l}10 \mathrm{mg} \\
\mathrm{L}^{-1} \\
\text { nano- } \\
\mathrm{TiO}_{2}\end{array}$ & $\begin{array}{l}763.01 \pm \\
30.69 \mathrm{bcd}\end{array}$ & $\begin{array}{l}163.70 \\
\pm 5.31 \\
\mathrm{~cd}\end{array}$ & $\begin{array}{l}211.50 \\
\pm 16.58 \\
d\end{array}$ & $\begin{array}{l}241.62 \pm \\
6.08^{f}\end{array}$ & $\begin{array}{l}130.86 \\
\pm 1.07 \mathrm{gh}\end{array}$ & $187.11 \pm 3.52 \mathrm{de}$ & $\begin{array}{l}86.35 \pm \\
0.52^{c}\end{array}$ \\
\hline & & $\begin{array}{l}60 \mathrm{mg} \\
\mathrm{L}^{-1} \\
\text { nano- } \\
\mathrm{TiO}_{2}\end{array}$ & $\begin{array}{l}1392.14 \\
\pm 37.77^{\mathrm{a}}\end{array}$ & $\begin{array}{l}236.74 \\
\pm 9.58^{a}\end{array}$ & $\begin{array}{l}341.74 \\
\pm 9.711^{\text {a }}\end{array}$ & $\begin{array}{l}376.87 \pm \\
17.83^{b}\end{array}$ & $\begin{array}{l}235.15 \\
\pm 5.11^{a}\end{array}$ & $244.50 \pm 4.35^{a}$ & $\begin{array}{l}113.39 \pm \\
2.08^{a}\end{array}$ \\
\hline & & $\begin{array}{l}120 \\
\mathrm{mg} \mathrm{L}^{-1} \\
\text { nano- } \\
\mathrm{TiO}_{2}\end{array}$ & $\begin{array}{l}785.39 \pm \\
53.58 \mathrm{bc}\end{array}$ & $\begin{array}{l}139.58 \\
\pm 5.99 \text { ef }\end{array}$ & $\begin{array}{l}257.13 \\
\pm 5.57^{c}\end{array}$ & $\begin{array}{l}278.18 \pm \\
7.96^{e}\end{array}$ & $\begin{array}{l}133.36 \\
\pm 7.25 \mathrm{gh}\end{array}$ & $159.79 \pm 1.56 \mathrm{gh}$ & $\begin{array}{l}59.29 \pm \\
0.53 \text { ghi }\end{array}$ \\
\hline & & $\begin{array}{l}50 \mu \mathrm{M} \\
\text { MeJa }\end{array}$ & $\begin{array}{l}711.91 \pm \\
7.11^{\mathrm{cd}}\end{array}$ & $\begin{array}{l}202.47 \\
\pm 13.82 \\
\mathrm{~b}\end{array}$ & $\begin{array}{l}263.41 \\
\pm 2.07^{c}\end{array}$ & $\begin{array}{l}402.56 \pm \\
4.79^{a}\end{array}$ & $\begin{array}{l}232.93 \\
\pm 5.21^{a}\end{array}$ & $202.40 \pm 4.31^{c}$ & $\begin{array}{l}87.28 \pm \\
0.60^{c}\end{array}$ \\
\hline & & $\begin{array}{l}100 \\
\mu \mathrm{M} \\
\mathrm{MeJa}\end{array}$ & $\begin{array}{l}439.15 \pm \\
9.23 \mathrm{ij}\end{array}$ & $\begin{array}{l}129.75 \\
\pm 0.89 \\
\text { efg }\end{array}$ & $\begin{array}{l}216.17 \\
\pm 5.06^{d}\end{array}$ & $\begin{array}{l}224.66 \pm \\
3.85^{f}\end{array}$ & $\begin{array}{l}143.64 \\
\pm 4.16^{f g}\end{array}$ & $179.78 \pm 1.44^{\mathrm{e}}$ & $\begin{array}{l}66.61 \pm \\
0.99^{f}\end{array}$ \\
\hline & & $\begin{array}{l}200 \\
\mu \mathrm{M} \\
\mathrm{MeJa}\end{array}$ & $\begin{array}{l}436.10 \pm \\
10.34^{k}\end{array}$ & $\begin{array}{l}119.68 \\
\pm 1.43 \mathrm{fg}\end{array}$ & $\begin{array}{l}157.04 \\
\pm 1.14^{\mathrm{e}}\end{array}$ & $\begin{array}{l}179.06 \pm \\
3.71^{\mathrm{hi}}\end{array}$ & $\begin{array}{l}164.09 \\
\pm 3.41 \mathrm{e}^{\mathrm{e}}\end{array}$ & $159.37 \pm 1.48 \mathrm{gh}$ & $\begin{array}{l}59.37 \pm \\
0.44 \text { ghi }\end{array}$ \\
\hline & \multirow[t]{6}{*}{$\begin{array}{l}\mathrm{BAP}_{0.5}+ \\
2,4-\mathrm{D}_{1.5} \\
\mathrm{mg} \mathrm{L}^{-1}\end{array}$} & $\begin{array}{l}\text { Control } \\
2(0)\end{array}$ & $\begin{array}{l}319.04 \pm \\
26.20^{k}\end{array}$ & $\begin{array}{l}109.75 \\
\pm 2.87 \mathrm{~g}\end{array}$ & $\begin{array}{l}151.58 \\
\pm 14.13 \\
\mathrm{e}\end{array}$ & $\begin{array}{l}179.83 \pm \\
8.41^{\mathrm{hi}}\end{array}$ & $\begin{array}{l}113.46 \\
\pm 4.39 \mathrm{ij}\end{array}$ & $100.74 \pm 6.51^{i}$ & $\begin{array}{l}49.29 \pm \\
0.54^{j}\end{array}$ \\
\hline & & $\begin{array}{l}10 \mathrm{mg} \\
\mathrm{L}^{-1} \\
\text { nano- } \\
\mathrm{TiO}_{2}\end{array}$ & $\begin{array}{l}493.69 \pm \\
55.96^{\mathrm{hi}}\end{array}$ & $\begin{array}{l}146.18 \\
\pm 8.29 \\
\text { de }\end{array}$ & $\begin{array}{l}202.70 \\
\pm 6.10^{d}\end{array}$ & $\begin{array}{l}238.86 \pm \\
6.70^{f}\end{array}$ & $\begin{array}{l}122.53 \\
\pm 3.65 \text { hij }\end{array}$ & $142.94 \pm 4.24 \mathrm{ij}$ & $\begin{array}{l}77.06 \pm \\
0.87 \mathrm{e}^{-}\end{array}$ \\
\hline & & $\begin{array}{l}60 \mathrm{mg} \\
\mathrm{L}^{-1} \\
\text { nano- } \\
\mathrm{TiO}_{2}\end{array}$ & $\begin{array}{l}839.74 \pm \\
36.01^{b}\end{array}$ & $\begin{array}{l}201.17 \\
\pm 7.55^{b}\end{array}$ & $\begin{array}{l}258.18 \\
\pm 9.44^{c}\end{array}$ & $\begin{array}{l}282.68 \pm \\
11.12^{\mathrm{e}}\end{array}$ & $\begin{array}{l}233.77 \\
\pm 6.03^{a}\end{array}$ & $199.32 \pm 4.07^{c}$ & $\begin{array}{l}90.71 \pm \\
0.81 \mathrm{~b}\end{array}$ \\
\hline & & $\begin{array}{l}120 \\
\mathrm{mg} \mathrm{L}^{-1} \\
\text { nano- } \\
\mathrm{TiO}_{2}\end{array}$ & $\begin{array}{l}609.68 \pm \\
62.73 \text { ef }\end{array}$ & $\begin{array}{l}125.31 \\
\pm 12.67 \\
\text { efg }\end{array}$ & $\begin{array}{l}305.75 \\
\pm 22.96 \\
b\end{array}$ & $\begin{array}{l}224.87 \pm \\
16.84^{f}\end{array}$ & $\begin{array}{l}166.74 \\
\pm 3.911^{\mathrm{e}}\end{array}$ & $142.42 \pm 5.63^{\mathrm{ij}}$ & $\begin{array}{l}68.26 \pm \\
0.51^{f}\end{array}$ \\
\hline & & $\begin{array}{l}50 \mu \mathrm{M} \\
\mathrm{MeJa}\end{array}$ & $\begin{array}{l}585.07 \pm \\
5.78^{\mathrm{fg}}\end{array}$ & $\begin{array}{l}205.44 \\
\pm 3.47^{b}\end{array}$ & $\begin{array}{l}282.13 \\
\pm 8.19 b c\end{array}$ & $\begin{array}{l}310.75 \pm \\
5.46^{d}\end{array}$ & $\begin{array}{l}220.38 \\
\pm 2.67^{b}\end{array}$ & $202.80 \pm 1.18^{c}$ & $\begin{array}{l}78.28 \pm \\
0.60 \mathrm{de}\end{array}$ \\
\hline & & $\begin{array}{l}100 \\
\mu \mathrm{M} \\
\mathrm{MeJa}\end{array}$ & $\begin{array}{l}473.13 \pm \\
7.37^{i}\end{array}$ & $\begin{array}{l}171.88 \\
\pm 3.92^{c}\end{array}$ & $\begin{array}{l}153.12 \\
\pm 1.45^{\mathrm{e}}\end{array}$ & $\begin{array}{l}215.00 \pm \\
2.91^{\mathrm{fg}}\end{array}$ & $\begin{array}{l}150.43 \\
\pm 5.29^{f}\end{array}$ & $167.77 \pm 2.28^{f g}$ & $\begin{array}{l}62.18 \pm \\
0.57^{\mathrm{g}}\end{array}$ \\
\hline
\end{tabular}




\begin{tabular}{|c|c|c|c|c|c|c|c|c|c|}
\hline $\begin{array}{l}\text { Explant } \\
\text { type }\end{array}$ & $\begin{array}{l}\text { Hormone } \\
\text { treatment }\end{array}$ & $\begin{array}{l}\text { Elicitor } \\
\text { type }\end{array}$ & $\begin{array}{l}\text { Phenolics } \\
\text { content } \\
\text { mg GAE } \\
100 \mathrm{~g}^{-1} \\
\text { DW }\end{array}$ & $\begin{array}{l}\begin{array}{l}\text { Total } 0 \\
\text { di } \\
\text { phenols }\end{array} \\
\text { mg GAE } \\
100 \mathrm{~g}^{-1} \\
\text { DW }\end{array}$ & $\begin{array}{l}\begin{array}{l}\text { Total } \\
\text { phenolic } \\
\text { acids }\end{array} \\
\text { mg CAE } \\
100 \mathrm{~g}^{-1} \\
\text { DW }\end{array}$ & $\begin{array}{l}\begin{array}{l}\text { Total } \\
\text { flavonoids }\end{array} \\
\text { mg CATE } \\
100 \mathrm{~g}^{-1} \\
\text { DW }\end{array}$ & $\begin{array}{l}\text { Total } \\
\text { flavone } \\
\& \\
\text { flavonol } \\
\text { mg QE } \\
100 \mathrm{~g}^{-1} \\
\text { DW }\end{array}$ & $\begin{array}{l}\text { Proanthocyanidins } \\
\text { mg CATE } 100 \mathrm{~g}^{-1} \\
\text { DW }\end{array}$ & $\begin{array}{l}\begin{array}{l}\text { Rosmarinic } \\
\text { acid }\end{array} \\
\text { mg } 100 \mathrm{~g}^{-} \\
{ }^{1} \text { DW }\end{array}$ \\
\hline & & $\begin{array}{l}200 \\
\mu \mathrm{M} \\
\text { MeJa }\end{array}$ & $\begin{array}{l}426.43 \pm \\
5.64^{i j}\end{array}$ & $\begin{array}{l}128.21 \\
\pm 7.06 \\
\text { efg }\end{array}$ & $\begin{array}{l}152.53 \\
\pm 4.86^{\mathrm{e}}\end{array}$ & $\begin{array}{l}162.98 \pm \\
5.82^{i}\end{array}$ & $\begin{array}{l}125.17 \\
\pm 3.67^{\mathrm{hi}}\end{array}$ & $196.27 \pm 1.15^{\mathrm{cd}}$ & $\begin{array}{l}56.28 \pm \\
0.60^{i}\end{array}$ \\
\hline & \multirow[t]{7}{*}{$\begin{array}{l}\mathrm{BAP}_{1}+ \\
2,4-\mathrm{D}_{0.5} \\
\mathrm{mg} \mathrm{L}^{-1}\end{array}$} & $\begin{array}{l}\text { Control } \\
3(0)\end{array}$ & $\begin{array}{l}292.56 \pm \\
9.42^{k}\end{array}$ & $\begin{array}{l}125.71 \\
\pm 1.84 \\
\text { efg }\end{array}$ & $\begin{array}{l}118.26 \\
\pm 4.20^{f}\end{array}$ & $\begin{array}{l}193.57 \pm \\
6.98 \mathrm{gh}\end{array}$ & $\begin{array}{l}110.32 \\
\pm 1.69^{\mathrm{j}}\end{array}$ & $99.48 \pm 6.52^{i}$ & $\begin{array}{l}43.28 \pm \\
0.72^{k}\end{array}$ \\
\hline & & $\begin{array}{l}10 \mathrm{mg} \\
\mathrm{L}^{-1} \\
\text { nano- } \\
\mathrm{TiO}_{2}\end{array}$ & $\begin{array}{l}453.96 \pm \\
28.00 \mathrm{ij}\end{array}$ & $\begin{array}{l}161.66 \\
\pm 5.14 \\
\text { efg }\end{array}$ & $\begin{array}{l}120.20 \\
\pm 7.59^{f}\end{array}$ & $\begin{array}{l}224.02 \pm \\
4.73^{f}\end{array}$ & $\begin{array}{l}140.90 \\
\pm 5.62 \mathrm{fg}\end{array}$ & $151.83 \pm 1.89 \mathrm{hi}$ & $\begin{array}{l}58.94 \pm \\
2.13 \mathrm{hi}\end{array}$ \\
\hline & & $\begin{array}{l}60 \mathrm{mg} \\
\mathrm{L}^{-1} \\
\text { nano- } \\
\mathrm{TiO}_{2}\end{array}$ & $\begin{array}{l}620.00 \pm \\
9.31 \text { ef }\end{array}$ & $\begin{array}{l}210.62 \\
\pm 6.14^{b}\end{array}$ & $\begin{array}{l}204.53 \\
\pm 13.61 \\
d\end{array}$ & $\begin{array}{l}349.11 \pm \\
14.13^{c}\end{array}$ & $\begin{array}{l}205.23 \\
\pm 3.35^{c}\end{array}$ & $221.25 \pm 2.90^{b}$ & $\begin{array}{l}88.31 \pm \\
1.05 \mathrm{bc}\end{array}$ \\
\hline & & $\begin{array}{l}120 \\
\mathrm{mg} \mathrm{L}^{-1} \\
\text { nano- } \\
\mathrm{TiO}_{2}\end{array}$ & $\begin{array}{l}567.12 \pm \\
3.71^{\mathrm{fgh}}\end{array}$ & $\begin{array}{l}214.82 \\
\pm 2.99 \mathrm{~b}\end{array}$ & $\begin{array}{l}163.08 \\
\pm 4.73^{\mathrm{e}}\end{array}$ & $\begin{array}{l}240.79 \pm \\
1.10^{f}\end{array}$ & $\begin{array}{l}122.15 \\
\pm 4.73 \text { hij }\end{array}$ & $136.49 \pm 7.33^{j}$ & $\begin{array}{l}61.55 \pm \\
1.71 \mathrm{gh}\end{array}$ \\
\hline & & $\begin{array}{l}50 \mu \mathrm{M} \\
\mathrm{MeJa}\end{array}$ & $\begin{array}{l}687.70 \pm \\
7.65 \mathrm{de}\end{array}$ & $\begin{array}{l}125.71 \\
\pm 1.84 \\
\text { efg }\end{array}$ & $\begin{array}{l}201.88 \\
\pm 1.19 \mathrm{~d}\end{array}$ & $\begin{array}{l}331.26 \pm \\
6.06^{\mathrm{cd}}\end{array}$ & $\begin{array}{l}210.18 \\
\pm 2.08 \text { bc }\end{array}$ & $221.22 \pm 1.49^{b}$ & $\begin{array}{l}80.39 \pm \\
1.47^{d}\end{array}$ \\
\hline & & $\begin{array}{l}100 \\
\mu \mathrm{M} \\
\mathrm{MeJa}\end{array}$ & $\begin{array}{l}426.31 \pm \\
7.94^{\mathrm{ij}}\end{array}$ & $\begin{array}{l}195.62 \\
\pm 3.10 \\
\text { bc }\end{array}$ & $\begin{array}{l}79 \pm \\
1.13^{f}\end{array}$ & $\begin{array}{l}230.99 \pm \\
9.38^{f}\end{array}$ & $\begin{array}{l}129.83 \\
\pm 2.66 \mathrm{gh}\end{array}$ & $157.42 \pm 1.70 \mathrm{gh}$ & $\begin{array}{l}51.93 \pm \\
0.33^{j}\end{array}$ \\
\hline & & $\begin{array}{l}200 \\
\mu \mathrm{M} \\
\text { MeJa }\end{array}$ & $\begin{array}{l}374.06 \pm \\
3.88^{\mathrm{jk}}\end{array}$ & $\begin{array}{l}120.96 \\
\pm 7.96 \mathrm{fg}\end{array}$ & $\begin{array}{l}153.05 \\
\pm 2.97 \mathrm{e}\end{array}$ & $\begin{array}{l}158.50 \pm \\
5.98^{i}\end{array}$ & $\begin{array}{l}187.97 \\
\pm 6.64\end{array}$ & $177.06 \pm 2.55$ ef & $\begin{array}{l}49.17 \pm \\
0.42^{j}\end{array}$ \\
\hline
\end{tabular}

\section{Assessment Of Antioxidant Activity}

Following the determination of the biophenolic contents, the antioxidant activities of all calli derived from apical meristem and leaf were evaluated by DPPH and FRAP radical scavenging assays. As can be seen in Figs. $2 A$ and $2 B, D P P H(P \leq 0.01)$ and FRAP $(P \leq 0.05)$ result illustrated that the highest antioxidant activity of apical meristem-derived callus $\left(\mathrm{IC}_{50} 23.33 \pm 2.27 \mu \mathrm{g} \mathrm{mL}^{-1}\right.$ and $475.77 \pm 22.39$ $\mathrm{mg} \mathrm{Fe}+2100 \mathrm{~g}^{-1} \mathrm{DW}$, respectively) was found after treatment with $10 \mathrm{mg} \mathrm{L}^{-1}$ nano-TiO 2 on the media containing "BAP $0.5+2,4-\mathrm{D}_{0.5}$ " $\mathrm{mg} \mathrm{L}^{-1}$. Moreover, the $\mathrm{IC}_{50}$ values of elicitor-treated extracts were near to ascorbic acid $\left(\mathrm{IC}_{50} 12.52 \pm 0.97 \mu \mathrm{g} \mathrm{mL}^{-1}\right)$.

The DPPH antioxidant activity in leaf-derived calli varied from $\left(\mathrm{IC}_{50} 88.31 \pm 5.14 \mu \mathrm{g} \mathrm{mL}^{-1}\right)$ to $\left(\mathrm{IC}_{50} 25.71 \pm 6.91 \mu \mathrm{g} \mathrm{mL}-1\right)$. The low-IC 50 value (as the highest antioxidant capacity) was observed in the presence of "BAP $0.5+2,4-\mathrm{D}_{1.5}$ " $\mathrm{mg} \mathrm{L}^{-1}$ and $60 \mathrm{mg} \mathrm{L}^{-1}$ nano-TiO $_{2}$ (Fig. 3A) followed by methanol extract of callus on media with $50 \mu \mathrm{M}$ MeJa and "BAP ${ }_{0.5}+2,4-\mathrm{D}_{1}$ " $\mathrm{mg} \mathrm{L}^{-1}$. The results from FRAP antioxidant assay revealed that all the extracts showed considerable antioxidant potency compared to the controls and the application of $60 \mathrm{mg} \mathrm{L}^{-1}$ nano- $\mathrm{TiO}_{2}$ and $50 \mu \mathrm{M}$ MeJa caused the highest amount of antioxidant activities (Fig. 3B).

The results of Pearson's correlation showed a significant and positive correlation $(P \leq 0.01)$ between estimated polyphenol derivatives and assayed antioxidant capacities. A very strong correlation was recorded between the content of rosmarinic acid of apical meristemderived calli and DPPH and FRAP values $\left(r^{2}=-0.921\right.$ and $r^{2}=-0.913, P<0.01$ respectively). While there were highly statistically significant correlations between total phenolic content of all extracts and two radicals scavenging assays, correlations of these assays 
with phenolic acids, flavonoids, flavones, and proanthocyanidins were somewhat weaker (Fig. 4). The weakest correlation occurred between the $O$-diphenols content of leaf-derived calli and DPPH scavenging activity and FRAP assay $\left(r^{2}=0.501\right.$ and $r^{2}=0.491$, respectively).

\section{Effect Of Elicitors On Specific Flavonoids Content}

Based on the results of flavonoids, flavone, and flavonols contents, two explant-derived calli with the highest ones were selected for quantitative analysis of Apigenin, Quercetin, and Rutin. For apical meristem-derived callus on the medium containing "BAP $0.5+2,4-D^{2}$ $0.5^{\prime \prime} \mathrm{mg} \mathrm{L}^{-1}$, the highest content of Apigenin $\left(0.134 \pm 0.007 \mu \mathrm{g} \mathrm{g}^{-1} \mathrm{DW}\right)$, Quercetin $\left(0.491 \pm 0.03 \mu \mathrm{g} \mathrm{g}^{-1} \mathrm{DW}\right)$ and Rutin $(2.941 \pm 0.13 \mu \mathrm{g}$ $\left.\mathrm{g}^{-1} \mathrm{DW}\right)$ were found after MeJa-elicitation $(50 \mu \mathrm{M})$. In callus of leaf explant on basal MS supplemented with "BAP $0.5+2,4-\mathrm{D}_{1}$ " $\mathrm{mg} \mathrm{L}^{-1}$, the maximum level of Apigenin $\left(0.330 \pm 0.02 \mathrm{\mu g} \mathrm{g}^{-1} \mathrm{DW}\right)$ were measured after exposure to $50 \mu \mathrm{M}$ MeJa, while the application of $60 \mathrm{mg}$ $\mathrm{L}^{-1}$ nano- $\mathrm{TiO}_{2}$ led to the highest concentration of Quercetin $\left(2.619 \pm 0.09 \mu \mathrm{g} \mathrm{g}^{-1} \mathrm{DW}\right)$ and Rutin $\left(13.792 \pm 0.87 \mu \mathrm{g} \mathrm{g}{ }^{-1} \mathrm{DW}\right)(\mathrm{Fig} .5)$.

\section{Discussion}

The combination of plant hormones in the medium has been reported necessary to stimulate a high frequency of callus induction (Hong et al. 2008; Giri et al. 2012). In this work, the simultaneous use of BAP and 2,4-D significantly increased callus induction rate so that the highest callogenesis rate was recorded for apical meristem explant on the medium augmented with" BAP $1+2,4-\mathrm{D}_{1}$ " mg L-1 and for leaf explant on the medium containing "BAP $0.5+2.4-\mathrm{D}_{1}$ " $\mathrm{mg} \mathrm{L}^{-1}$. Hemmati et al. (2020) studies on $S$. tebesana also showed a similar result of the promotive effect of BAP and 2,4-D in callus production of different explants. The results of Hussein's research on the callus induction potential of S. officinalis hypocotyl indicated the enhancing effects of BAP and 2,4-D (Hussein et al. 2014). The positive influence of simultaneous use of BAP and 2,4-D for callogenesis was also reported earlier for several Salvia species (Lemraski et al. 2014; Modarres et al. 2018) and other plant species (Wang and Bao 2007; El-shafey et al. 2019). A remarkable point is a balance between auxin and cytokinin in the culture medium as a key regulator of in vitro callogenesis, leading to increased cell division as an important process for callus induction (Johri and Mitra 2001; Roy and Banerjee 2003).

The results of the present study showed that regardless of the type of elicitor used, the calluses of both apical meristem and leaf explants on MS medium supplemented with the lower concentrations of auxin (2,4-D) and cytokinin (BAP) can produce more phenolic compounds compared with other combination ratios of 2,4-D and BAP. Similarly, the research of Hemmati et al. (2020) on Salvia tebesana showed that the low combinations of 2,4-D $\left(0.5 \mathrm{mg} \mathrm{L}^{-1}\right)$ and BAP $\left(0.5\right.$ and $\left.1 \mathrm{mg} \mathrm{L}^{-1}\right)$ caused the maximum phenolic accumulation in callus obtained from shoot apical meristem and leaf explants, but Chaâbani et al. (2015) confirmed MS medium supplemented with $2.0 \mathrm{mg} \mathrm{L}^{-1}$ 2,4-D and $1.0 \mathrm{mg} \mathrm{L}^{-1}$ BAP seemed to be the most suitable medium for the highest production of total phenols in leaf-derived callus of Crataegus azarolus $\mathrm{L}$. var. aronia in comparison to lower 2,4-D/BAP ratio. In agreement with our results, Maharik et al. (2009) and El-Baz et al. (2010) suggested that the addition of a lower level of auxin (NAA) to the culture medium than BAP yielded the most phenolic derivatives contents in in vitro cultures. The type and concentration of plant hormones in the culture medium influence the pathways involved producing secondary metabolites (Adie et al. 2007). The biosynthesis of most phenolics dominantly takes place through the shikimate/arogenate pathway producing three amino acids of tryptophan, tyrosine, and phenylalanine. These amino acids are also involved in the synthesis of some hormones, in particular auxins (Ruiz and Romero 2001). Phenylalanine ammonia-lyase (PAL) and tyrosine ammonia-lyase (TAL) are the key enzymes of this pathway (Acamovic and Brooker 2005). Due to the confirmed effect of auxin (IAA and 2,4-D) on gene expression of these enzymes, as well the activation or the inhibition of their activities, the variation in the biosynthesis rate of phenolic compounds is normally happening (Tanaka and Uritani 1979; Chaâbani et al. 2015).

Based on the obtained results, both nano- $\mathrm{TiO}_{2}$ and MeJa was stimulating the production of polyphenols compared to controls. In treatment with nanoparticles, the application of $10 \mathrm{mg} \mathrm{L}^{-1}$ nano- $\mathrm{TiO}_{2}$ and $60 \mathrm{mg} \mathrm{L}^{-1}$ nano- $\mathrm{TiO}_{2}$ led to the most increase of phenolic derivatives in calluses derived from apical meristem and leaf, respectively; which were about 1.5 times higher than the amounts observed in other nano- $\mathrm{TiO}_{2}$ treated samples. The promotive effect of nano- $\mathrm{TiO}_{2}$ elicitor on phenolic compounds accumulation has also been recorded in seedling of S. officinalis (Ghorbanpour 2015), seedling of S. officinalis (Mazarie et al. 2019), cell culture of Aloe vera (Raei et al. 2014), and in vitro cultures of other species such as Papaver somniferum (Khodayari et al. 2014) and Lallemantia iberica (Sattari et al. 2020). It has been suggested that the use of nanoparticles in plant cell culture is highly important to produce secondary metabolites (Asl et al. 2019). Due to cause oxidative stress in target cells (Aghdam et al. 2016; Mohammadi et al. 2014), non- 
bio-elicitors including nanoparticles stimulate the plant to increase immune responses and increase $P A L$ gene expression, leading to an increase in secondary metabolites, especially phenolic compounds, which are a part of the systemic acquired resistance process (Rajendran et al. 1994, Feizi et al. 2012; Singh et al. 2012). Studies have also shown that elicitors, including nano elicitors, have a positive effect on increasing the absorption of some nutrients, especially nitrates, leading to increased expression of genes involved in the synthesis of phenolic compounds (Bais et al. 2004; Lemraski et al. 2014; Baenas et al. 2014; Kavianifar et al. 2018; Rivero-Montejo et al. 2021). However, studies have shown that the effects of $\mathrm{TiO}_{2}$ nanoparticles are highly concentration-dependent; so that if the concentration exceeded the particular threshold, the adverse and cytotoxic effects will appear in plants (Ghosh et al. 2010; Rafique et al. 2014; Mohammadi et al. 2016). Similar results regarding a decreased promotive effect of nano- $-\mathrm{TiO}_{2}$ at higher concentrations have been obtained by Raei et al. (2014), who showed that the treatment with $120 \mathrm{mg} \mathrm{L}^{-1}$ nano-TiO ${ }_{2}$ reduced the amount of Aloin in the tissue culture of Aloe vera. It is stated that treatment with non-optional concentrations of nano elicitors probably can cause the overproduction amount of oxidative materials and disturbance in the cellular redox balance leading to many severe damages to plant cell structures, proteins, and DNA (Afaq et al. 1998; Raei et al. 2014; Rafique et al. 2014). The destructive effect on DNA and negative consequence on gene expression eventually lead to a decrease in the production of active substances (Lok et al. 2006; Raei et al. 2016).

In this work, the pattern of phenolic derivatives accumulations in MeJa-elicited calli varied in an elicitor concentration-dependent manner. In a way that $50 \mu \mathrm{M}$ MeJa had a dramatically stimulating effect on the analyzed compounds, and with increasing the levels of MeJa to $200 \mu \mathrm{M}$, the concentration of all phenolics decreased by almost half. Remarkably, the MeJa at $50 \mu \mathrm{M}$ was also more effective at enhancing the total flavonoids and its individuals' content in calli obtained from both explants in comparison with the best nano-TiO ${ }_{2}$ treatments $\left(10\right.$ and $60 \mathrm{mg} \mathrm{L}^{-1}$ ). This result is in agreement with the findings reported by Hashemyan et al. (2020) for Teucrium polium, with emphasis on the lower MeJa-elicitation $(50 \mu \mathrm{M})$ for the highest contents of polyphenols. More promotive effects of the lower dose of exogenously applied MeJa on phenolic, flavonoid and/or phenolic acid contents were informed in shoot culture of $S$. virgata (11.2

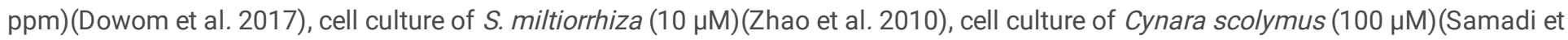
al. 2019), cell suspension culture of Thevetia peruviana (3 $\mu \mathrm{M})$ (Mendoza et al. 2018), callus suspension culture of Habenaria edgeworthii $(10 \mu \mathrm{M})$ (Giri et al. 2012), shoot culture of Centella asiatica $(50 \mu \mathrm{M})($ Skrzypczak-Pietraszek et al. 2019) and root culture of Polygonum multiflorum $(50 \mu \mathrm{M})$ ( Ho et al. 2018). Induced production of reactive oxygen species (ROS) and reactive nitrogen species (RNS) has been suggested as one of the potent signaling processes in the MeJa-treated elicitation leading to the overproduction of secondary metabolites, including polyphenols (Walker et al. 2002; Kim et al. 2005). Over-activation or activation of the phenylpropanoid pathway genes, PAL (Wang et al. 2005; Sun et al. 2013), CHS (Suzuki et al. 2005; Sánchez-Sampedro et al. 2005), C4H (Wang et al. 2014; Yousefian et al. 2020), and $4 C L$ (Yu et al. 2019; Yousefian et al. 2020) under conditions of MeJa treatment would be the reasons for these influence. Taking into account the results of many researches, the burst of oxidative stress and subsequent toxicity damage has been observed in plant samples exposed to a high level of MeJa (Scandalios et al. 1993; Di-Qiu et al. 1999; Mir et al. 2019; Ho et al. 2020). So it is important to optimize the MeJa concentration for improving secondary metabolite synthesis in in vitro culture system (Ho et al. 2020).

Phenolic and flavonoid compounds can protect cells from oxidation by electrolyzing and purifying the ROS produced by the electron transfer system in optical synthesis (Shen et al. 2009). The significant positive influence of increasing phenolic derivatives contents on antioxidant activities, due to the elicitation of nanoparticles and methyljasmonate (summarized in Fig. 4), show that the callus of $S$. tebesana is a potent scavenger of free radicals. The present data were in line with the results of experiments on $S$. verticillata (Tepe et al. 2007), S. officinalis (Grzegorczyk and Wysoklńska 2009; Ghorbanpour 2015; Vosoughi et al. 2018), S. miltiorrhiza (Dong et al. 2010), S. tebesana (Hemmati et al. 2020), S. nemorosa (Heydari et al. 2020), S. multicaulis (Salehi et al. 2018), Nepeta binaloudensis (Sagharyan et al. 2019), Graecoanatolica dinarica (Krstić-Milošević et al. 2017), Orthosiphon stamineus (Lim et al. 2013), indicating the relationship between the concentration of phenolic compounds and antioxidant properties. Meanwhile, some differences in the order of the samples between the DPPH and FRAP assays of "methanolic extracts" of both explants-derived callus may be ascribed to the different solvents used in each assay (Kouka et al. 2017).

\section{Conclusion}

In conclusion, it was successfully determined that $S$. tebesana has good callogenesis potential, with the highest callogenesis rate and callus dry weight for explants on MS media supplemented with the combined combination of BAP $\left(0.5\right.$ and $\left.1 \mathrm{mg} \mathrm{L}^{-1}\right)$ and 2,4-D (1 mg $\mathrm{L}^{-1}$ ). Also, the present study showed that elicitation with nano- $\mathrm{TiO}_{2}$ and $\mathrm{MeJa}$ at low concentrations, significantly promote the production of predominant phenolic derivatives in S. tebesana calli. Additionally, in increasing of rosmarinic acid, Quercetin, and Rutin, nano- $\mathrm{TiO}_{2}$ treatment was more effective than MeJa elicitation. Our results showed that the combination of in vitro culture and 
elicitation would be a good technique to successfully produce and enhance the content of pharmacologically valuable metabolites in S. tebesana.

\section{Abbreviations}

MS Murashige and Skoog medium

2,4-D 2,4-dichlorophenoxyacetic acid

BAP 6-Benzylaminopurine

DW Dry weight

FW Fresh weight

Nano- $\mathrm{TiO}_{2}$ Titanium dioxide nanoparticles

MeJa Methyl jasmonate

FRAP Ferric Reducing Antioxidant Power

DPPH 2,2-Diphenyl-1-picrylhydrazyl

IC Inhibitory concentration

RA Rosmarinic acid

\section{Declarations}

The authors declare that they have no relevant conflict of interest.

\section{Acknowledgments}

This research was financially supported by Ferdowsi University of Mashhad, Iran (Grant no. 2/52724). The Authors have no conflicts of interest to declare. The authors would like to thank Mr. Seyed Yahya Tarahomi for his graphical assistance.

\section{References}

1. Acamovic T, Brooker J (2005) Biochemistry of plant secondary metabolites and their effects in animals. Proceedings of the Nutrition Society 64: 403-412. https://doi.org/10.1079/PNS2005449

2. Adie BA, Pérez-Pérez J, Pérez-Pérez MM, Godoy M, Sánchez-Serrano JJ, Schmelz EA, Solano R (2007) ABA is an essential signal for plant resistance to pathogens affecting JA biosynthesis and the activation of defenses in Arabidopsis. The Plant Cell 19: 16651681. https://doi.org/10.1105/tpc.106.048041

3. Afaq F, Abidi P, Matin R, Rahman Q (1998) Cytotoxicity, pro-oxidant effects and antioxidant depletion in rat lung alveolar macrophages exposed to ultrafine titanium dioxide, Journal of Applied Toxicology: An International Forum Devoted to Research and Methods Emphasizing Direct Clinical, Industrial and Environmental Applications, Wiley Online Library, pp 307-

312. https://doi.org/10.1002/(SICI)1099-1263(1998090)18:5<307::AID-JAT508>3.0.C0;2-K

4. Aghdam MTB, Mohammadi H, Ghorbanpour M (2016) Effects of nanoparticulate anatase titanium dioxide on physiological and biochemical performance of Linum usitatissimum (Linaceae) under well-watered and drought stress conditions. Brazilian Journal of Botany 39: 139-146. https://doi.org/10.1007/s40415-015-0227-x

5. Aleebrahim-Dehkordy E, Bahmani M, Rafieian-Kopaei M (2016) Phytochemical, pharmacological, and biochemical characteristics of essential oil of some Salvia L. species. Journal of Chemical and Pharmaceutical Sciences 9: 3395-3402.

6. Annegowda HV, Bhat R, Min-Tze L, Karim AA, Mansor SM (2012) Influence of sonication treatments and extraction solvents on the phenolics and antioxidants in star fruits. Journal of Food Science and Technology 49: 510-514. https://doi.org/10.1007/s13197-

Page $15 / 24$ 
011-0435-8

7. Asl KR, Hosseini B, Sharafi A, Palazon J (2019) Influence of nano-zinc oxide on tropane alkaloid production, h6h gene transcription and antioxidant enzyme activity in Hyoscyamus reticulatus L. hairy roots. Engineering in Life Sciences 19: 73-

89. https://doi.org/10.1002/elsc.201800087

8. Baenas N, García-Viguera, C, Moreno DA (2014) Elicitation: a tool for enriching the bioactive composition of foods. Molecules 19 : 13541-13563. https://doi.org/10.3390/molecules190913541

9. Bahreini M, Omidi M, Bondarian F, Gholibaygian M (2015) Metabolites screening of nano elicited in vitro Iranian fennel (Foeniculum vulgare). American Journal of Biology and Life Sciences 3: 194-198.

10. Bais HP, Park SW, Weir TL, Callaway RM, Vivanco JM (2004) How plants communicate using the underground information superhighway. Trends in Plant Science 9: 26-32. https://doi.org/10.1016/j.tplants.2003.11.008

11. Bandoniene D, Murkovic M, Venskutonis PR (2005) Determination of rosmarinic acid in sage and borage leaves by highperformance liquid chromatography with different detection methods. Journal of Chromatographic Science 43: 372-

6. https://doi.org/10.1093/chromsci/43.7.372

12. Baskaran P, Ncube B, Van Staden J (2012) In vitro propagation and secondary product production by Merwilla plumbea (Lindl.) Speta. Plant Growth Regulation 67: 235-245. https://doi.org/10.1007/s10725-012-9682-6

13. Carrasco-Pancorbo A, Cerretani L, Bendini A, Segura-Carretero A, Del Carlo M, Gallina-Toschi T, Fernandez-Gutierrez A (2005) Evaluation of the antioxidant capacity of individual phenolic compounds in virgin olive oil. Journal of Agricultural and Food Chemistry 53: 818-825. https://doi.org/10.1021/jf0515680

14. Chaâbani G, Tabart J, Kevers C, Dommes J, Khan MI, Zaoui S, Chebchoub L, Lachaâl M, Karray-Bouraoui N (2015) Effects of 2,4dichlorophenoxyacetic acid combined to 6-Benzylaminopurine on callus induction, total phenolic and ascorbic acid production, and antioxidant activities in leaf tissue cultures of Crataegus azarolus L. var. aronia. Acta Physiologiae Plantarum 37 (2):

16. https://doi.org/10.1007/s11738-014-1769-4

15. de Torre MP, Cavero RY, Calvo MI, Vizmanos JL (2019) A simple and a reliable method to quantify antioxidant activity in vivo. Antioxidants 8 (5): 142. https://doi.org/10.3390/antiox8050142

16. Di-Qiu Y, Chuan C, Ming-Lan Y, Bao-Jian L (1999) Studies on the Salicylic Acid Inducted Lipid Peroxidation and Defense Gene Expression in Tobacco Cell Culture. Journal of Integrative Plant Biology 41: 977-983.

17. Dong J, Wan G, Liang Z (2010) Accumulation of salicylic acid-induced phenolic compounds and raised activities of secondary metabolic and antioxidative enzymes in Salvia miltiorrhiza cell culture. Journal of biotechnology 148: 99-

104. https://doi.org/10.1016/j.jbiotec.2010.05.009

18. Đorđević S, Cakić M, Amr S (2000) The extraction of apigenin and luteolin from the sage Salvia officinalis L. from Jordan. Facta universitatis-series: Working and Living Environmental Protection 1: 87-93.

19. Dowom SA, Abrishamchi P, Rajabian T, Salami SA (2017) Enhanced phenolic acids production in regenerated shoot cultures of Salvia virgata Jacq. after elicitation with $\mathrm{Ag}^{+}$ions, methyl jasmonate and yeast extract. Industrial Crops and Products 103: 8188. https://doi.org/10.1016/j.indcrop.2017.03.043

20. Eghbaliferiz S, Emami SA, Tayarani-Najaran Z, Iranshahi M, Shakeri A, Hohmann J, Asili J (2018) Cytotoxic diterpene quinones from Salvia tebesana Bunge. Fitoterapia 128: 97-101. https://doi.org/10.1016/j.fitote.2018.05.005

21. El-Baz FK, Mohamed AA, Ali SI (2010) Callus formation, phenolics content and related antioxidant activities in tissue culture of a medicinal plant colocynth (Citrullus colocynthis). Nova Biotechnologica 10: 79-94.

22. El-Shafey N, Sayed M, Ahmed E, Hammouda O, Khodary SE (2019) Effect of growth regulators on micropropagation, callus induction and callus flavonoid content of Rumex pictus Forssk. Egyptian Journal of Botany 59: 293-

302. https://doi.org/10.21608/EJBO.2019.4873.1202

23. Feizi $\mathrm{H}$, Moghaddam PR, Shahtahmassebi N, Fotovvat A (2012) Impact of bulk and nanosized titanium dioxide $\left(\mathrm{TiO}_{2}\right)$ on wheat seed germination and seedling growth. Biological Trace Element Research 146: 101-106. https://doi.org/10.1007/s12011-0119222-7

24. Fotovvat M, Rajabian T, Saboora A (2018) HPLC fingerprint of important phenolic compounds in some Salvia L. species from Iran. Records of Natural Products 13: 37-49. https://doi.org/10.25135/rnp.72.18.02.228

25. Ge X, Wu J (2005) Induction and potentiation of diterpenoid tanshinone accumulation in Salvia miltiorrhiza hairy roots by $\beta$ aminobutyric acid. Applied Microbiology and Biotechnology 68: 183-188. https://doi.org/10.1007/s00253-004-1873-2 
26. Ghorbanpour M (2015) Major essential oil constituents, total phenolics and flavonoids content and antioxidant activity of Salvia officinalis plant in response to nano-titanium dioxide. Indian Journal of Plant Physiology 20: 249-

256. https://doi.org/10.1007/s40502-015-0170-7

27. Ghosh $\mathrm{M}$, Bandyopadhyay $\mathrm{M}$, Mukherjee $\mathrm{A}$ (2010) Genotoxicity of titanium dioxide $\left(\mathrm{TiO}_{2}\right)$ nanoparticles at two trophic levels: plant and human lymphocytes. Chemosphere 81: 1253-1262. https://doi.org/10.1016/j.chemosphere.2010.09.022

28. Giri L, Dhyani P, Rawat S, Bhatt ID, Nandi SK, Rawal RS, Pande V (2012) In vitro production of phenolic compounds and antioxidant activity in callus suspension cultures of Habenaria edgeworthir: a rare Himalayan medicinal orchid. Industrial Crops and Products 39: 1-6. https://doi.org/10.1016/j.indcrop.2012.01.024

29. Goldansaz SM, Hakimi Meybodi MH, Mirhosseini A, Mirjalili MH (2017) Essential oil composition of Salvia tebesana Bunge (Lamiaceae) from Iran. Records of Natural Products 11: 310-314.

30. Gómez JD, Vital CE, Oliveira MG, Ramos HJ (2018) Broad range flavonoid profiling by LC/MS of soybean genotypes contrasting for resistance to Anticarsia gemmatalis (Lepidoptera: Noctuidae). PloS one 13:

e0205010. https://doi.org/10.1371/journal.pone.0205010

31. Grzegorczyk I, Wysoklńska H (2009) The effect of methyl jasmonate on production of antioxidant compounds in shoot cultures of Salvia officinalis L. Herba Polonica 55: 238-243.

32. Hasanloo T, Rezazadeh S, Rahnama H (2009) Hairy Roots as a Source for Production of Valuable Pharmaceutical Materials. Journal of Medicinal Plants 4: 1-17.

33. Hashemyan M, Ganjeali A, Cheniany M (2020) Effect of Methyl Jasmonate and Salicylic Acid Elicitors on the Production of Secondary Metabolites and Antioxidant Capacity of Teucrium polium L. in-vitro. Iranian Journal of Plant Biology 12: 6176. https://doi.org/10.22108/IJPB.2020.118410.1164

34. Hemmati N, Cheniany M, Ganjeali A (2020) Effect of plant growth regulators and explants on callus induction and study of antioxidant potentials and phenolic metabolites in Salvia tebesana Bunge. Botanica Serbica 44: 163-

173. https://doi.org/10.2298/BOTSERB2002163H

35. Heydari HR, Chamani E, Esmaielpour B (2020) Cell line selection through gamma irradiation combined with multi-walled carbon nanotubes elicitation enhanced phenolic compounds accumulation in Salvia nemorosa cell culture. Plant Cell, Tissue and Organ Culture (PCTOC) 142: 353-367. https://doi.org/10.1007/s11240-020-01867-6

36. Ho TT, Lee JD, Jeong CS, Paek KY, Park SY (2018) Improvement of biosynthesis and accumulation of bioactive compounds by elicitation in adventitious root cultures of Polygonum multiflorum. Applied Microbiology and Biotechnology 102: 199-

209. https://doi.org/10.1007/s00253-017-8629-2

37. Ho TT, Murthy HN, Park SY (2020) Methyl jasmonate induced oxidative stress and accumulation of secondary metabolites in plant cell and organ cultures. International Journal of Molecular Sciences 21 (3): 716.

38. Hoagland DR, Arnon DI (1950) The water-culture method for growing plants without soil. Circular. California agricultural experiment station 347. https://doi.org/10.3390/ijms21030716

39. Hong PI, Chen JT, Chang WC (2008) Plant regeneration via protocorm-like body formation and shoot multiplication from seedderived callus of a media type slipper orchid. Acta Physiologiae Plantarum 30: 755-759. https://doi.org/10.1007/s11738-008-01582

40. Hussein Y, Amin G, Hashem E, Youssef K (2014) In vitro cultivation of marjoram (Origanum majorana L.) under influence of 2, 4-D (2, 4-Dichlorophenoxy Acetic Acid) as herbicide. Life Science Journal 11: 102-146.

41. Jadeja R, Devkar R (2014) Polyphenols in chronic diseases and their mechanisms of action. Polyphenols in Human Health and Disease 1: 615-623.

42. Johri M, Mitra D (2001) Action of plant hormones. Current Science 80: 199-205.

43. Kamatou GP, Makunga N, Ramogola W, Viljoen AM (2008) South African Salvia species: a review of biological activities and phytochemistry. Journal of Ethnopharmacology 119: 664-672. https://doi.org/10.1016/j.jep.2008.06.030

44. Kavianifar S, Ghodrati K, Naghdi Badi H, Etminan A (2018) Effects of Nano Elicitors on Callus Induction and Mucilage Production in Tissue Culture of Linum usitatissimum L. Journal of Medicinal Plants 17: 45-54.

45. Khatamzaz M (2002) Flora of Iran, Research Institute of Forests and Rangelands Publications. Familay Boraginaceae, 504.

46. Khodayari M, Omidi M, Shahnejat Bushehri A (2014) Effect of a biotic elicitor and nano elicitor on some alkaloids production in Papaver somniferum L. Iranian Journal of Horticulture 7, (3):287-295.

Page $17 / 24$ 
47. Kim BJ, Gibson DM, Shuler ML (2005) Relationship of viability and apoptosis to taxol production in Taxus sp. suspension cultures elicited with methyl jasmonate. Biotechnology Progress 21: 700-707. https://doi.org/10.1021/bp050016z

48. Kosalec I, Bakmaz M, Pepeljnjak S, Vladimir-Knezevic SANDA (2004) Quantitative analysis of the flavonoids in raw propolis from northern Croatia. Acta Pharmaceutica-Zagreb 54(1): 65-72.

49. Koşar M, Göger F, Can Başer KH (2008) In vitro antioxidant properties and phenolic composition of Salvia virgata Jacq. from Turkey. Journal of Agricultural and Food Chemistry 56: 2369-2374. https://doi.org/10.1021/jf073516b

50. Kouka P, Priftis A, Stagos D, Angelis A, Stathopoulos P, Xinos N, Skaltsounis AL, Mamoulakis C, Tsatsakis AM, Spandidos DA, Spandidos DA (2017) Assessment of the antioxidant activity of an olive oil total polyphenolic fraction and hydroxytyrosol from a Greek Olea europea variety in endothelial cells and myoblasts. International Journal of Molecular Medicine 40: 703712. https://doi.org/10.3892/ijmm.2017.3078

51. Krstić-Milošević D, Janković T, Uzelac B, Vinterhalter D, Vinterhalter B (2017) Effect of elicitors on xanthone accumulation and biomass production in hairy root cultures of Gentiana dinarica. Plant Cell, Tissue and Organ Culture 130: 631640. https://doi.org/10.1007/s11240-017-1252-1

52. Lemraski MG, Eftekhari M, Faraji M, Zarrini SS (2014) Study of callus induction in common sage (Salvia officinalis L.). International Journal of Agriculture and Crop Sciences 7: 386-389.

53. Li T, Elhadi D, Chen GQ (2017) Co-production of microbial polyhydroxyalkanoates with other chemicals. Metabolic Engineering 43: 29-36. https://doi.org/10.1016/j.ymben.2017.07.007

54. Lim FL, Yam MF, Asmawi MZ, Chan LK (2013) Elicitation of Orthosiphon stamineus cell suspension culture for enhancement of phenolic compounds biosynthesis and antioxidant activity. Industrial crops and products 50: 436442. https://doi.org/10.1016/j.indcrop.2013.07.046

55. Lok CN, Ho CM, Chen R, He QY, Yu WY, Sun H, Tam PKH, Chiu JF, Che CM (2006) Proteomic analysis of the mode of antibacterial action of silver nanoparticles. Journal of Proteome Research 5: 916-924.

56. Maharik N, Elgengaihi S, Taha H (2009) Anthocyanin production in callus cultures of Crataegus sinaica boiss. International Journal of Academic Research 1: 30-34. https://doi.org/10.1021/pr0504079

57. Marinova D, Ribarova F, Atanassova M (2005) Total phenolics and total flavonoids in Bulgarian fruits and vegetables. Journal of the University of Chemical Technology and Metallurgy 40(3): 255-26.

58. Matkowski A, Zielińska S, Oszmiański J, Lamer-Zarawska E (2008) Antioxidant activity of extracts from leaves and roots of Salvia miltiorrhiza Bunge, S. przewalskii Maxim. and S. verticillata L. Bioresource Technology 99: 78927896. https://doi.org/10.1016/j.biortech.2008.02.013

59. Mazarie A, Mousavi-nik SM, Ghanbari A, Fahmideh L (2019) Effect of titanium dioxide spraying on physiological characteristics of sage (Salvia officinalis L.) under water stress. Environmental Stresses in Crop Sciences 12: 539-

553. https://doi.org/10.22077/ESCS.2019.1369.1304

60. Mendoza D, Cuaspud O, Arias JP, Ruiz O, Arias M (2018) Effect of salicylic acid and methyl jasmonate in the production of phenolic compounds in plant cell suspension cultures of Thevetia peruviana. Biotechnology Reports 19: e00273. https://doi.org/10.1016/j.btre.2018.e00273

61. Mir MY, Hamid S, Kamili AN, Hassan QP (2019) Sneak peek of Hypericum perforatum L.: phytochemistry, phytochemical efficacy and biotechnological interventions. Journal of Plant Biochemistry and Biotechnology 28: 357373. https://doi.org/10.1007/s13562-019-00490-7

62. Modarres M, Bahabadi SE, Yazdi MET (2018) Enhanced production of phenolic acids in cell suspension culture of Salvia leriifolia Benth. using growth regulators and sucrose. Cytotechnology 70: 741-750. https://doi.org/10.1007/s10616-017-0178-0

63. Mohammadi $\mathrm{H}$, Esmailpour $\mathrm{M}$, Gheranpaye $\mathrm{A}$ (2016) Effects of $\mathrm{TiO}_{2}$ nanoparticles and water-deficit stress on morpho-physiological characteristics of dragonhead (Dracocephalum moldavica L.) plants. Acta Agriculturae Slovenica 107: 385-

396. http://dx.doi.org/10.14720/aas.2016.107.2.11

64. Mohammadi R, Maali-Amiri R, Mantri N (2014) Effect of $\mathrm{TiO}_{2}$ nanoparticles on oxidative damage and antioxidant defense systems in chickpea seedlings during cold stress. Russian Journal of Plant Physiology 61: 768-

775. https://doi.org/10.1134/S1021443714050124

65. Ourmazdi P, Chalabian F (2006) Tissue culture and organogenesis of Salvia nemorosa. Iranian Journal of Rangelands and Forests Plant Breeding and Genetic Research 14: 69-79. 
66. Öztürk M, Duru ME, İnce B, Harmandar M, Topçu G (2010) A new rapid spectrophotometric method to determine the rosmarinic acid level in plant extracts. Food Chemistry 123: 1352-1356. https://doi.org/10.1016/j.foodchem.2010.06.021

67. Petersen M, Simmonds MS (2003) Rosmarinic acid. Phytochemistry 62: 121-125. https://doi.org/10.1016/S0031-9422(02)00513-7

68. Raei M, Angaji SA, Omidi M, Khodayari M (2014) Effect of abiotic elicitors on tissue culture of Aloe vera. International Journal of Biosciences 5: 74-81. http://dx.doi.org/10.12692/ijb/5.1.74-81

69. Raei M, Esna-Ashari M, Khodayari M (2016) Abiotic elicitors and medicinal plants biotechnology. Journal of Cell and Tissue 7: $333-$ 342.

70. Rafique R, Arshad M, Khokhar M, Qazi I, Hamza A, Virk N (2014) Growth response of wheat to titania nanoparticles application. NUST Journal of Engineering Sciences 7: 42-46. https://doi.org/10.24949/njes.v7i1.133

71. Rajendran L, Suvarnalatha G, Ravishankar G, Venkataraman L (1994) Enhancement of anthocyanin production in callus cultures of Daucus canota L. under the influence of fungal elicitors. Applied Microbiology and Biotechnology 42: 227-

231. https://doi.org/10.1007/BF00902721

72. Rivero-Montejo SDJ, Vargas-Hernandez M, Torres-Pacheco I (2021) Nanoparticles as Novel Elicitors to Improve Bioactive Compounds in Plants. Agriculture 11 (2): 134. https://doi.org/10.3390/agriculture11020134

73. Roy J, Banerjee N (2003) Induction of callus and plant regeneration from shoot-tip explants of Dendrobium fimbriatum Lindl. var. oculatum Hk. f. Scientia Horticulturae 97: 333-340. https://doi.org/10.1016/S0304-4238(02)00156-5

74. Ruiz JM, Romero L (2001) Bioactivity of the phenolic compounds in higher plants. Studies in Natural Products Chemistry 25: 651654. https://doi.org/10.1016/S1572-5995(01)80020-X

75. Russo A, Formisano C, Rigano D, Senatore F, Delfine S, Cardile V, Rosselli S, Bruno M (2013) Chemical composition and anticancer activity of essential oils of Mediterranean sage (Salvia officinalis L.) grown in different environmental conditions. Food and Chemical Toxicology 55: 42-47. https://doi.org/10.1016/j.fct.2012.12.036

76. Sagharyan M, Ganjeali A, Cheniany M (2019) Investigating the effect of antioxidant compounds and various concentrations of BAP and NAA on the improvement of in vitro stem and root formation of Nepeta binaloudensis Jamzad. Nova Biologica Reperta 6: 198205.

77. Salehi F, Arouiee H, Naghdi Badi H, Nemati S, Tolyat Abulhassani S (2018) Evaluation of Morphophysiological and Phytochmical Traits of Different Ecotypes of Salvia multicaulis Vahl. in Hamedan Province, Iran. Journal of Medicinal Plants 4: 123-136.

78. Samadi S, Ghasemnajad A, Alizadeh M (2019) Fresh weigh, Total phenol, Total flavonoids, Antioxidant and PAL enzyme activity of stevia callus variation affected by salicylic acid and methyl jasmonate. Journal of Plant Process and Function 32: 325-337.

79. Sánchez-Sampedro M.A, Fernández-Tárrago J, Corchete P (2005) Yeast extract and methyl jasmonate-induced silymarin production in cell cultures of Silybum marianum (L.) Gaertn. Journal of Biotechnology 119: 6069. https://doi.org/10.1016/j.jbiotec.2005.06.012

80. Sattari NS, Jamei R, Eslam BP, Lisar SYS (2020) Interaction of Bulk and Nano Titanium Dioxide on Antioxidant Activity of Lallemantia iberica under Drought Conditions. Journal of Stress Physiology and Biochemistry 16 (2): 32-44.

81. Scandalios JG (1993) Oxygen stress and superoxide dismutases. Plant Physiology 101(1): 712. https://doi.org/10.1104/pp.101.1.7

82. Singh A, Dwivedi P (2018) Methyl-jasmonate and salicylic acid as potent elicitors for secondary metabolite production in medicinal plants: A review. Journal of Pharmacognosy and Phytochemistry 7: 750-757.

83. Shen Y, Jin L, Xiao P, Lu Y, Bao J (2009) Total phenolics, flavonoids, antioxidant capacity in rice grain and their relations to grain color, size and weight. Journal of Cereal Science 49: 106-111. https://doi.org/10.1016/j.jcs.2008.07.010

84. Skrzypczak-Pietraszek E, Słota J, Pietraszek J (2014) The influence of L-phenylalanine, methyl jasmonate and sucrose concentration on the accumulation of phenolic acids in Exacum affine Balf. f. ex Regel shoot culture. Acta Biochimica Polonica 61: 47-53. https://doi.org/10.18388/abp.2014_1922

85. Skrzypczak-Pietraszek E, Urbańska A, Żmudzki P, Pietraszek J (2019) Elicitation with methyl jasmonate combined with cultivation in the Plantform ${ }^{\text {TM }}$ temporary immersion bioreactor highly increases the accumulation of selected centellosides and phenolics in Centella asiatica (L.) Urban shoot culture. Engineering in Life Sciences 19: 931-943. https://doi.org/10.1002/elsc.201900051

86. Sun B, Da-Silva JM, Spranger I (1998) Critical factors of vanillin assay for catechins and proanthocyanidin. Journal of Agricultural and Food Chemistry 46(10): 4267-4274. https://doi.org/10.1021/jf980366j 
87. Sun D, Lu X, Hu Y, Li W, Hong K, Mo Y, Cahill DM, Xie J (2013) Methyl jasmonate induced defense responses increase resistance to Fusarium oxysporum f. sp. cubense race 4 in banana. Scientia Horticulturae 164: 484-

491. https://doi.org/10.1016/j.scienta.2013.10.011

88. Suzuki H, Reddy MS, Naoumkina M, Aziz N, May GD, Huhman DV, Sumner LW, Blount JW, Mendes P, Dixon RA (2005) Methyl jasmonate and yeast elicitor induce differential transcriptional and metabolic re-programming in cell suspension cultures of the model legume Medicago truncatula. Planta 220: 696-707. https://doi.org/10.1007/s00425-004-1387-2

89. Taârit MB, Msaada K, Hosni K, Marzouk B (2012) Fatty acids, phenolic changes and antioxidant activity of clary sage (Salvia sclarea L.) rosette leaves grown under saline conditions. Industrial Crops and Products 38: 58-

63. https://doi.org/10.1016/j.indcrop.2012.01.002

90. Tanaka Y, Uritani I (1979) Effect of auxin and other hormones on the metabolic response to wounding in sweet potato roots. Plant and Cell Physiology 20: 157-164. https://doi.org/10.1093/oxfordjournals.pcp.a075958

91. Tepe B, Eminagaoglu O, Akpulat H.A, Aydin E (2007) Antioxidant potentials and rosmarinic acid levels of the methanolic extracts of Salvia verticillata (L.) subsp. verticillata and S. verticillata (L.) subsp. amasiaca (Freyn \& Bornm.) Bornm. Food Chemistry 100: $985-$ 989. https://doi.org/10.1016/j.foodchem.2005.10.062

92. Ulubelen A, Topcu G (1992) Abietane diterpenoids from Salvia pomifera. Phytochemistry Journal 31: 349351. ttps://doi.org/10.1016/S0031-9422(00)97560-5

93. Vosoughi N, Gomarian M, Pirbalouti AG, Khaghani S, Malekpoor F (2018) Essential oil composition and total phenolic, flavonoid contents, and antioxidant activity of sage (Salvia officinalis L.) extract under chitosan application and irrigation frequencies. Industrial Crops and Products 117: 366-374. https://doi.org/10.1016/j.indcrop.2018.03.021

94. Walker JB, Sytsma KJ, Treutlein J, Wink M (2004) Salvia (Lamiaceae) is not monophyletic: implications for the systematics, radiation, and ecological specializations of Salvia and tribe Mentheae. American Journal of Botany 91: 115125. https://doi.org/10.3732/ajb.91.7.1115

95. Walker TS, Bais HP, Vivanco JM (2002) Jasmonic acid-induced hypericin production in cell suspension cultures of Hypericum perforatum L. (St. John's wort). Phytochemistry 60: 289-293. https://doi.org/10.1016/S0031-9422(02)00074-2

96. Wang J, Bao MZ (2007) Plant regeneration of pansy (Viola wittrockiana) 'Caidie' via petiole-derived callus. Scientia Horticulturae 111: 266-270. https://doi.org/10.1016/j.scienta.2006.10.011

97. Wang J, Qian J, Yao L, Lu Y (2015) Enhanced production of flavonoids by methyl jasmonate elicitation in cell suspension culture of Hypericum perforatum. Bioresources and Bioprocessing 2: 1-9. https://doi.org/10.1186/s40643-014-0033-5

98. Wang JW, Wu JY (2005) Nitric oxide is involved in methyl jasmonate-induced defense responses and secondary metabolism activities of Taxus cells. Plant and Cell Physiology 46: 923-930. https://doi.org/10.1093/pcp/pci098

99. Wang S, Guo LP, Xie T, Yang J, Tang JF, Li X, Wang X, Huang LQ (2014) Different secondary metabolic responses to MeJa treatment in shikonin-proficient and shikonin-deficient cell lines from Arnebia euchroma (Royle) Johnst. Plant Cell, Tissue and Organ Culture 119: 587-598. https://doi.org/10.1007/s11240-014-0558-5

100. Yousefian S, Lohrasebi T, Farhadpour M, Haghbeen K (2020) Effect of methyl jasmonate on phenolic acids accumulation and the expression profile of their biosynthesis-related genes in Mentha spicata hairy root cultures. Plant Cell, Tissue and Organ Culture 142: 285-297. https://doi.org/10.1007/s11240-020-01856-9

101. Yu W, Yu M, Zhao R, Sheng J, Li Y, Shen L (2019) Ethylene perception is associated with methyl-jasmonate-mediated immune response against Botrytis cinerea in Tomato fruit. Journal of Agricultural and Food Chemistry 67: 67256735. https://doi.org/10.1021/acs.jafc.9b02135

102. Zhao DX, Fu CX, Han YS, Lu DP (2005) Effects of elicitation on jaceosidin and hispidulin production in cell suspension cultures of Saussurea medusa. Process Biochemistry, 40: 739-745. https://doi.org/10.1016/j.procbio.2004.01.040

103. Zhao JL, Zhou LG, Wu JY (2010) Effects of biotic and abiotic elicitors on cell growth and tanshinone accumulation in Salvia miltiorrhiza cell cultures. Applied Microbiology and Biotechnology 87: 137-144. https://doi.org/10.1007/s00253-010-2443-4

104. Zhishen J, Mengcheng T, Jianming W (1999) The determination of flavonoid contents in mulberry and their scavenging effects on superoxide radicals. Food Chemistry 64: 555-559. https://doi.org/10.1016/S0308-8146(98)00102-2

\section{Figures}




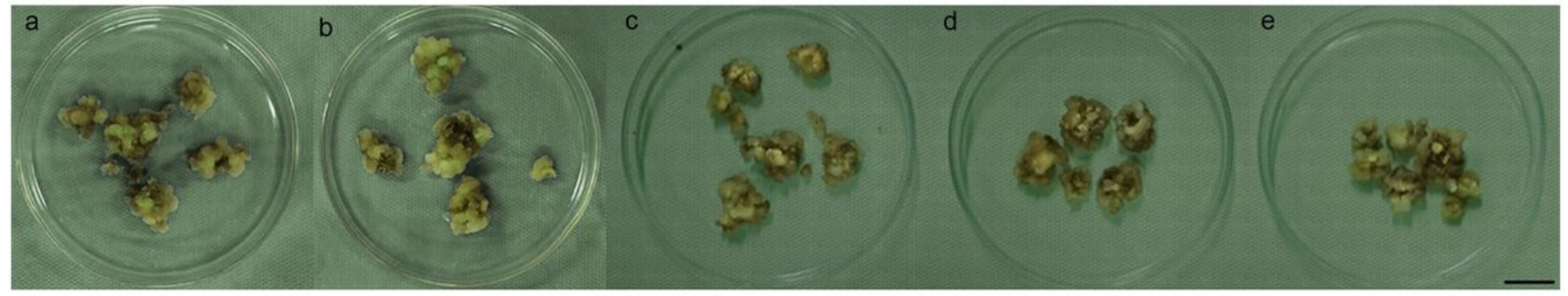

\section{Figure 1}

View of calluses with the highest percentage of callogenesis and dry weight of (a): apical meristem explant on medium with "BAP $1+$ 2,4-D 1" mg L-1, (b): apical meristem explant on medium with "BAP 0.5 + 2,4-D 0.5" mg L-1 (c): leaf explant on medium with " BAP 0.5 + 2,4-D 1.5 " mg L-1 (d): leaf explant on medium with "BAP $0.5+2.4$-D 1" mg L-1 and (e): leaf explant on medium with "BAP $1+2.4$-D 0.5 " $\mathrm{mg}$ L-1. Scale bar $=1 \mathrm{~cm}$.

a

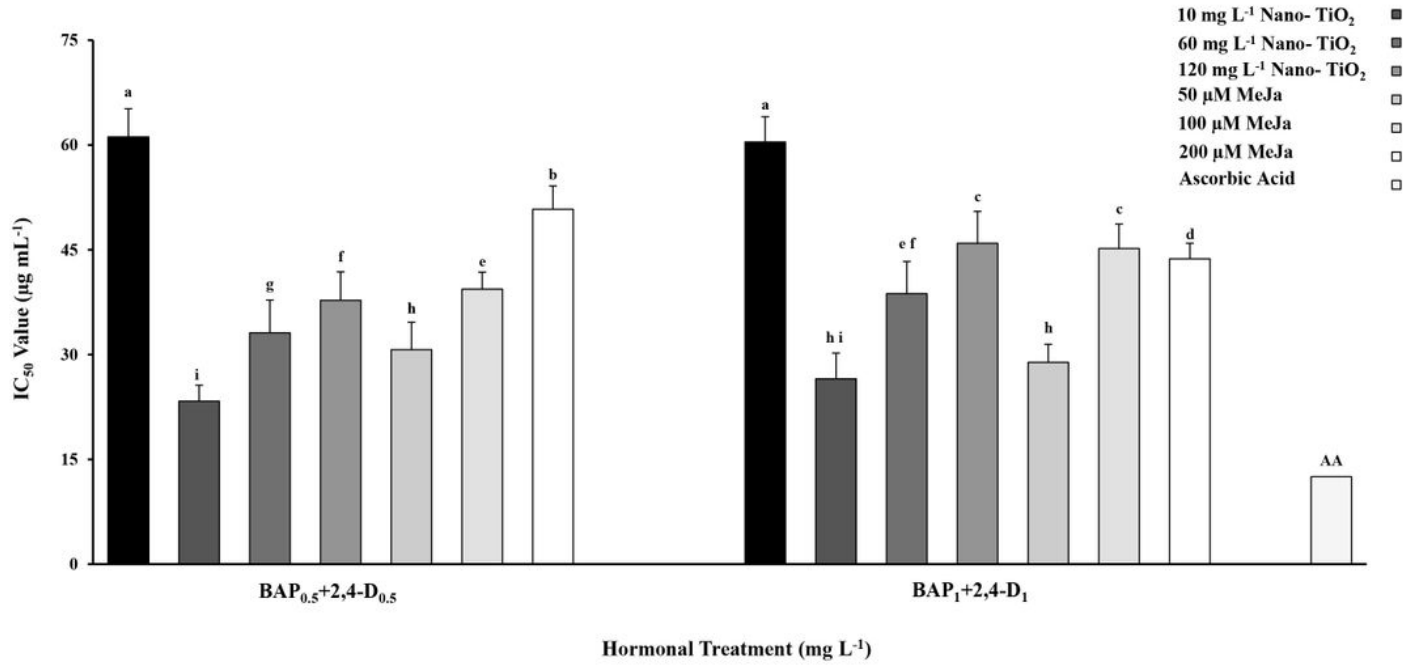

b

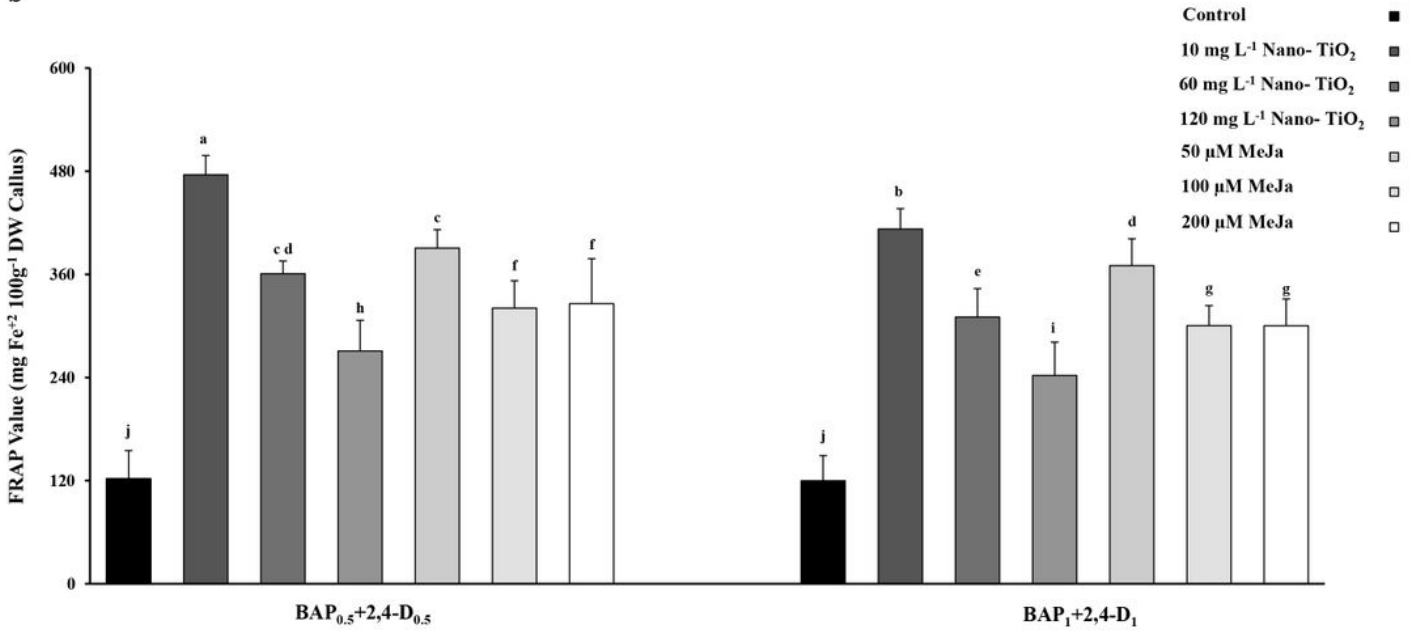

Hormonal Treatment ( $\mathrm{mg} \mathrm{L}^{-1}$ )

\section{Figure 2}

Antioxidant activity was assessed using DPPH (a) and FRAP (b) assays in apical meristem-derived callus. IC50 represents the levels of biophenols required to scavenge $50 \%$ of DPPH radicals. All data are expressed as the mean \pm SE. AA, Ascorbic acid. 
a

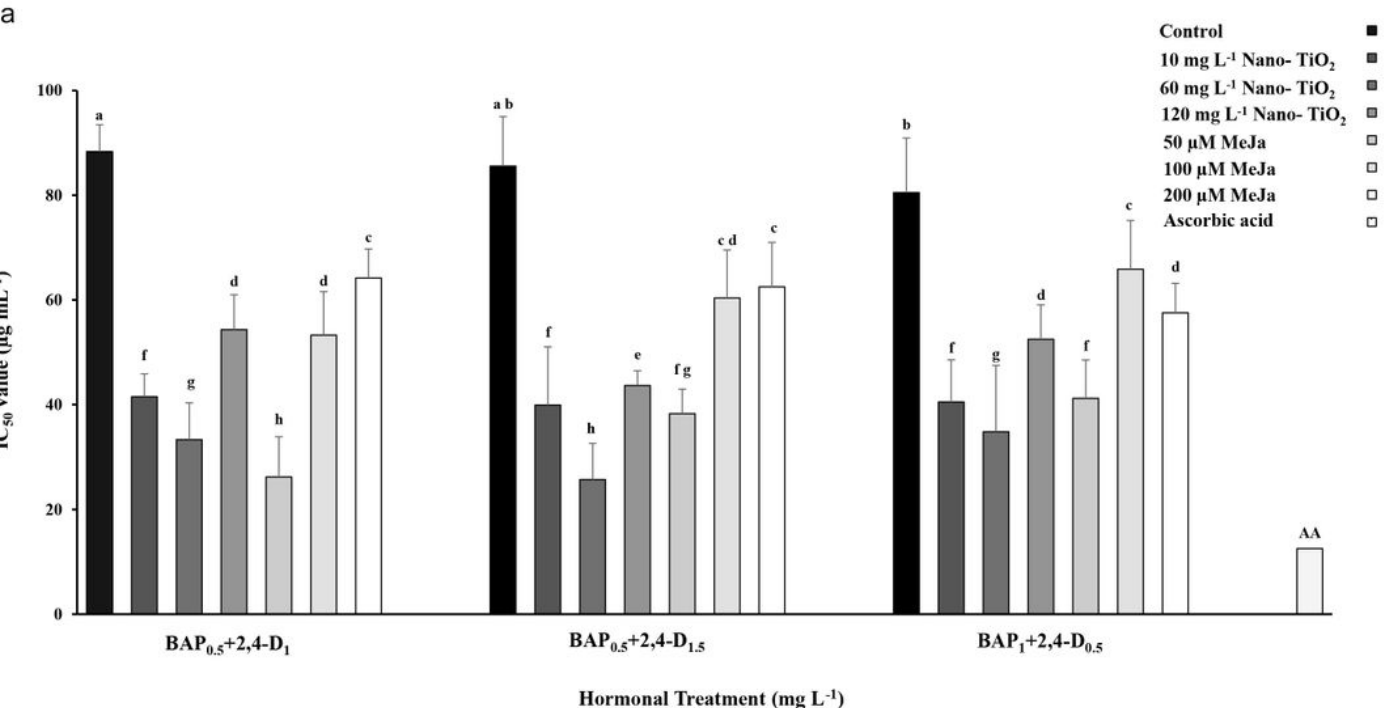

b

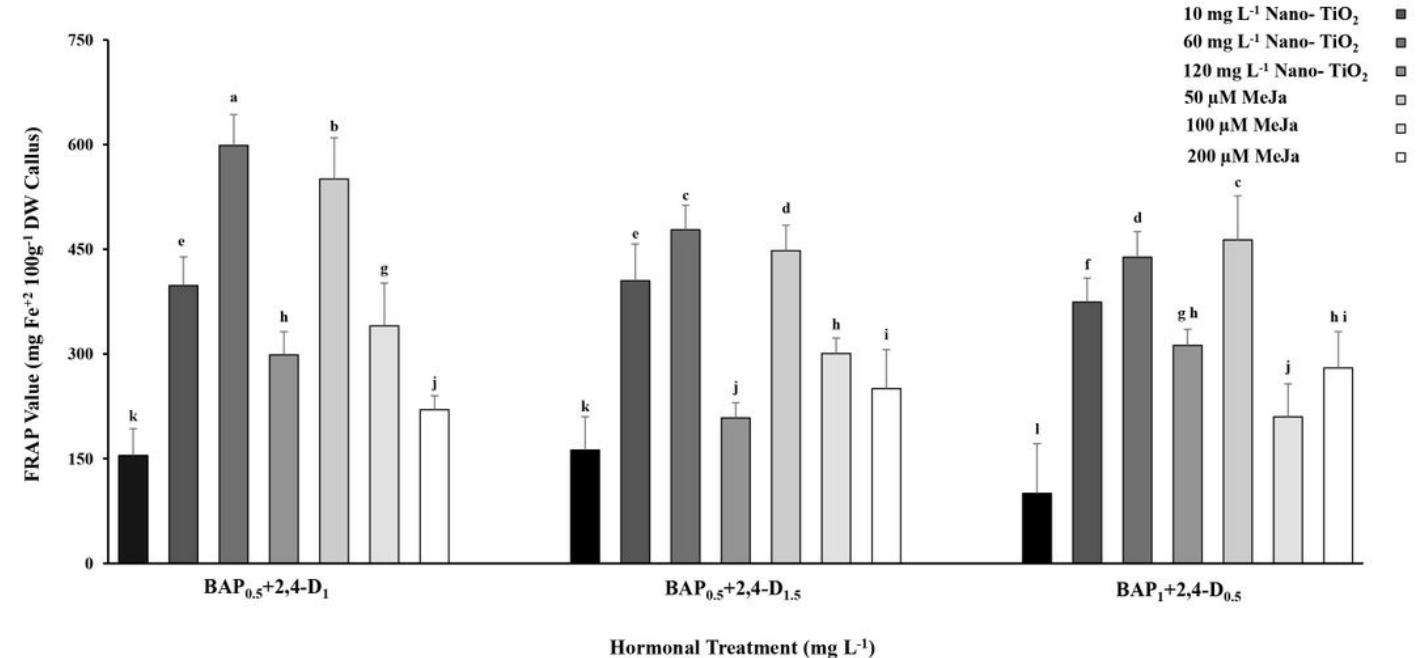

Figure 3

Antioxidant activity was assessed using DPPH (a) and FRAP (b) assays in leaf-derived callus. IC50 represents the levels of biophenols required to scavenge $50 \%$ of DPPH radicals. All data are expressed as the mean \pm SE. AA, Ascorbic acid. 
a

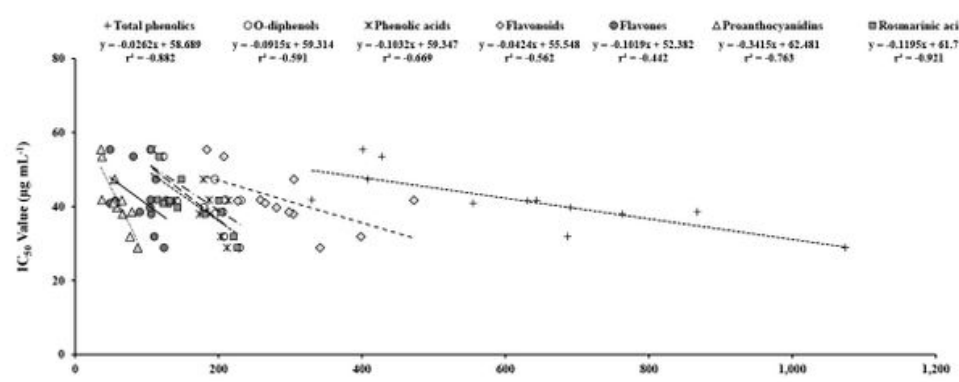

C

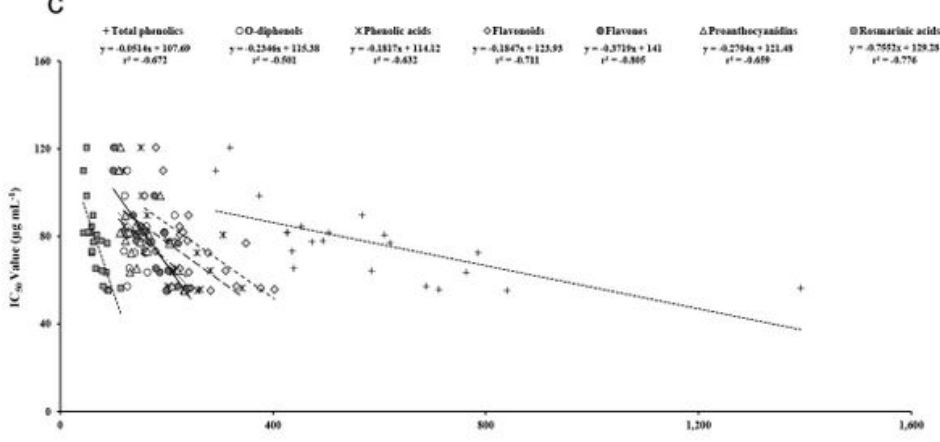

b

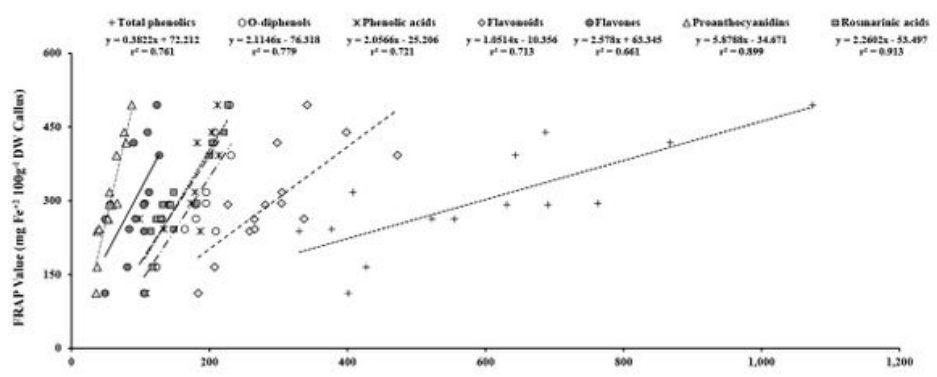

d

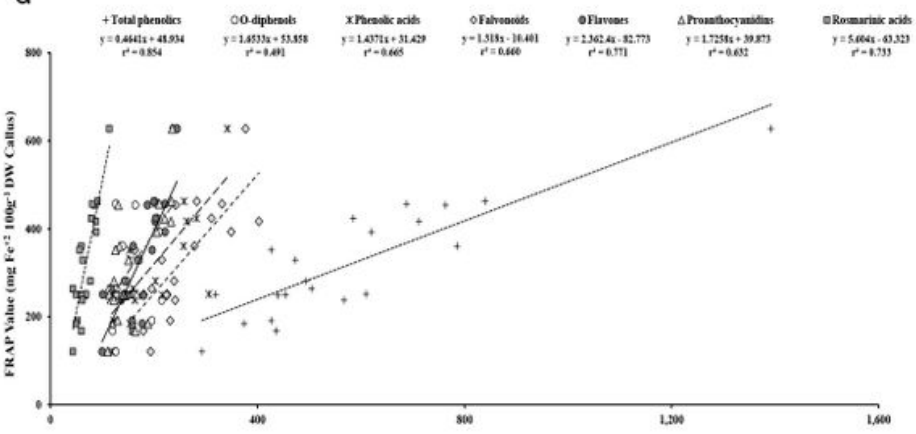

\section{Figure 4}

Linear correlation coefficients between phenolic composition and antioxidant capacity: in apical meristem-derived callus (a and b), and in leaf-derived callus (c and d). * Correlation is significant at the 0.01 level. 

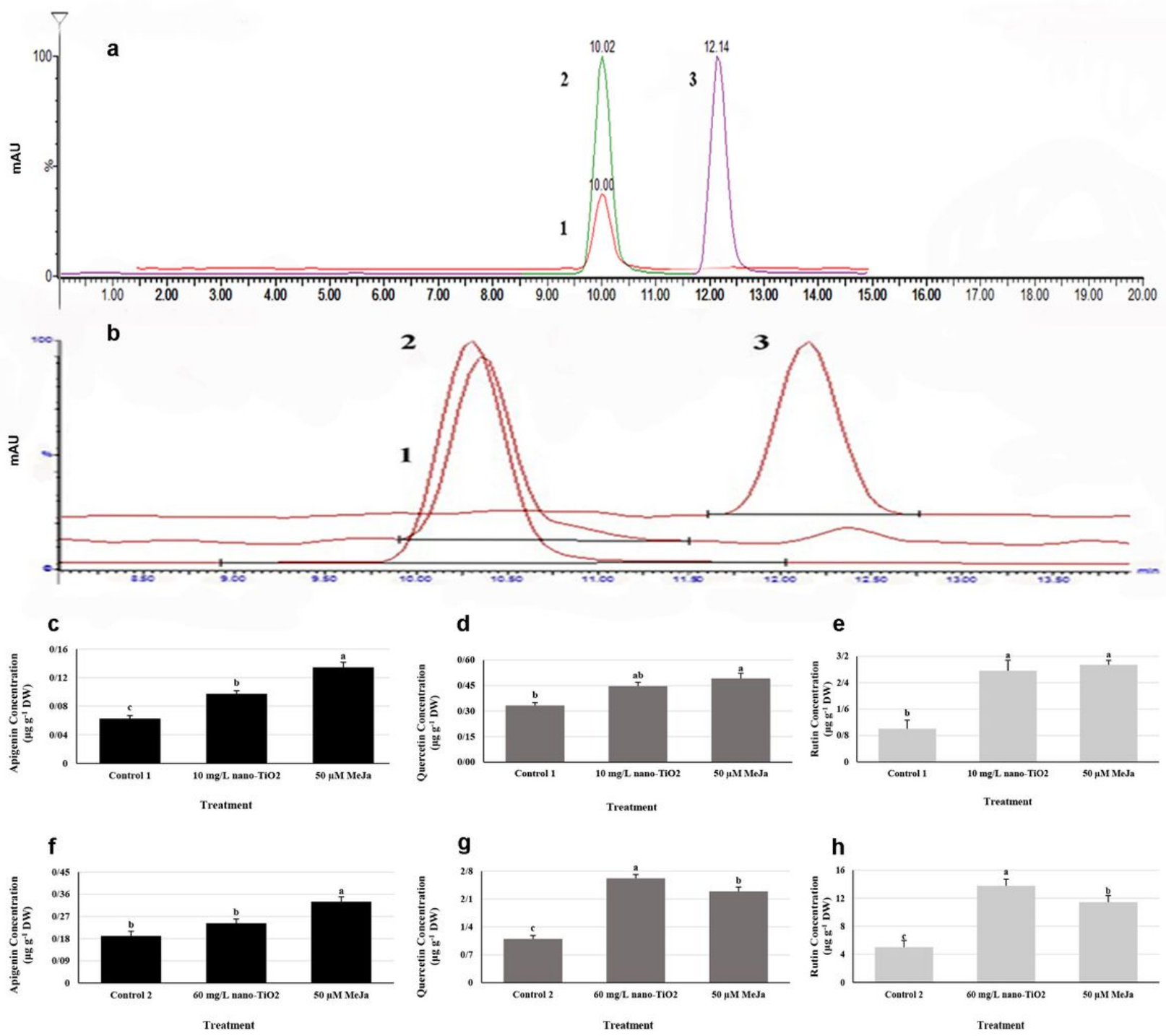

\section{Figure 5}

Choromatogram of standard samples of (1) Quercetin, (2) Rutin, and (3) Apigenin (a); Choromatogram of leaf-derived callus extract on MS medium supplemented with "BAP 0.5 + 2,4-D 1" mg L-1 and 60 mg L-1 TiO2 (b); LC/MS analysis of Apigenin, Quercetin and Rutin content in treated and non-treated samples of apical meristem-derived callus on the medium containing "BAP 0.5 + 2,4-D 0.5" mg L-1 (c, $\mathrm{d}, \mathrm{e})$; and leaf-derived callus on the medium containing "BAP $0.5+2,4-\mathrm{D} 1$ " $\mathrm{mg} \mathrm{L}-1$ (f, g, h). Each value represents mean \pm SE. 